\title{
Variable speed operation of centrifugal pumps running as turbines. Experimental investigation
}

\author{
J. Delgado ${ }^{\text {a, b, }}{ }^{*}$, J.P. Ferreira ${ }^{a}$, D.I.C. Covas ${ }^{a}$, F. Avellan ${ }^{\text {b }}$ \\ ${ }^{a}$ CERIS, Instituto Superior Técnico, Universidade de Lisboa, Av. Rovisco Pais, 1, 1049-001, Lisboa, Portugal \\ ${ }^{\mathrm{b}}$ Laboratory for Hydraulic Machines, École Polytechnique Fédérale de Lausanne, Avenue de Cour 33 bis, 1007 Lausanne, Switzerland
}

\section{A R T I C L E I N F O}

\section{Article history:}

Received 18 May 2018

Received in revised form

16 March 2019

Accepted 14 April 2019

Available online 17 April 2019

\section{Keywords:}

Pumps running as turbines

Variable speed

Energy recovery

Turbine mode

Four quadrants

Experimental investigation

\begin{abstract}
A B S T R A C T
Pumps running as turbines are pointed out as a cost-effective solution for energy recovery in pressurised water supply systems. However, these hydraulic machines feature low efficiency under variable discharge operation due to the lack of an inlet flow control component. Variable speed operation is an approach for controlling the discharge at the pump as turbine inlet aiming at increasing the operational efficiency. This research work presents the experimental investigation for measuring the variable speed characteristic curves of pumps running as turbines, focusing on the turbine and on the extended operation modes. Three single-stage end-suction closed-impeller centrifugal pumps with different unit specific speed values are tested. Turbine mode test results show that the discharge-specific energy operating range is broadened with increasing efficiency if the machines are operated with variable speed. Extended operation results show that these hydraulic machines do not feature the instability region near the runaway conditions, the so-called the "s-curve". Outcomes of this experimental investigation provide the required insights for establishing the design technical specifications of micro hydropower plants with variable speed pumps running as turbines, aiming at maximizing the energy recovered in pressurised water supply systems.
\end{abstract}

(c) 2019 Elsevier Ltd. All rights reserved.

\section{Introduction}

Pressurised water supply systems (WSS) have a significant potential for harvesting energy [1,2]. Locations for energy recovery in these infrastructures are defined as the sites where the flow is conveyed with an excessive pressure, not required for the effective downstream water supply. The scope of the average head and discharge available for energy recovery in WSS is very broad and infrastructure dependent, as illustrated in Fig. 1. The average head and discharge data presented in this figure are compiled from multiple site locations available in several literature references [3-20] and may be clustered into five types of WSS: (i) irrigation networks, (ii) inlet of water treatment plants; (iii) inlet of storage tanks or break pressure tanks, in trunks mains; (iv) pressure reducing valves in water distribution networks; and ( $v$ ) outlet of wastewater treatment plants.

\footnotetext{
* Corresponding author. CERIS, Instituto Superior Técnico, Universidade de Lisboa, Av. Rovisco Pais, 1, 1049-001, Lisboa, Portugal.

E-mail addresses: joao.borga.delgado@tecnico.ulisboa.pt, joao.delgado@epfl.ch (J. Delgado).
}

The operating range breakdown of discharge $Q$, head $H$, and hydraulic power $P_{\mathrm{h}}$, for each infrastructure is detailed in Table 1 . Irrigation infrastructures feature the highest discharge values as agriculture is far more water-intensive than drinking water supply [21]. Differences between water distribution networks, storage tanks and water treatment plants are justified to the water supply chain. Water treatment plants convey water to several storage tanks, while these supply several district meter areas, where pressure reducing valves (PRV) are usually installed. The head values in the above-mentioned infrastructures have the same order of magnitude, while wastewater treatment plants feature a lower range in this parameter.

The orders of magnitude of WSS operating conditions are smaller compared to conventional hydropower plants. According to these data, $85 \%$ of the sites have an available hydraulic power lower than $1 \mathrm{MW}$. In fact, the scope found for WSS (Fig. 1) is not matched by custom-made hydropower units, as illustrated in Fig. 2. Therefore, the deployment of energy recovery systems in these infrastructures is relying on hydraulic machines that can meet such operating conditions. The unit specific speed $n_{\mathrm{q}}$ represented in Fig. 2 is defined by Eq. (1). The computation of this parameter 


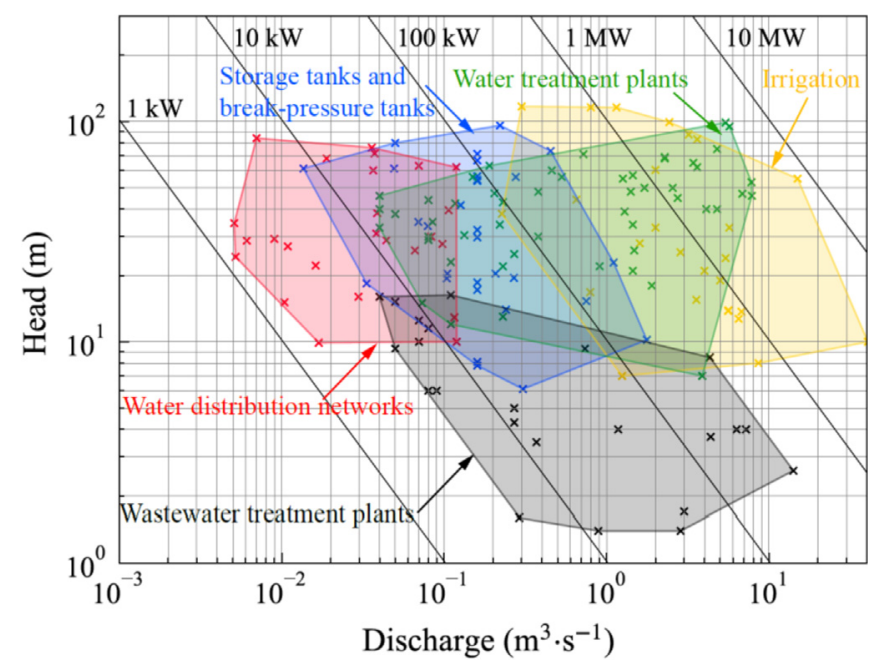

Fig. 1. Average head and discharge available for energy recovery in water supply systems. The isolines represent the available hydraulic power. Data is compiled from [3-20].

Table 1

Breakdown of minimum and maximum values of available discharge, head and hydraulic power for energy recovery in different WSS infrastructure types.

\begin{tabular}{|c|c|c|c|c|c|c|}
\hline \multirow[t]{2}{*}{ Location } & \multicolumn{2}{|c|}{$Q\left(\mathrm{~m}^{3} \cdot \mathrm{s}^{-1}\right)$} & \multicolumn{2}{|c|}{$H(\mathrm{~m})$} & \multicolumn{2}{|c|}{$P_{\mathrm{h}}(\mathrm{kW})$} \\
\hline & $\min$ & $\max$ & $\min$ & $\max$ & $\min$ & $\max$ \\
\hline Irrigation networks & 0.230 & 40.0 & 7.0 & 120 & 85 & 8100 \\
\hline Water treatment plants (inlet) & 0.040 & 7.8 & 6.0 & 100 & 11 & 5300 \\
\hline Storage tanks (inlet) & 0.015 & 1.8 & 6.0 & 100 & 6 & 325 \\
\hline Water distribution networks (PRV) & 0.005 & 0.12 & 10.0 & 85 & 1 & 75 \\
\hline Wastewater treatment plants (outlet) & 0.040 & 14.0 & 1.5 & 16 & 5 & 360 \\
\hline
\end{tabular}

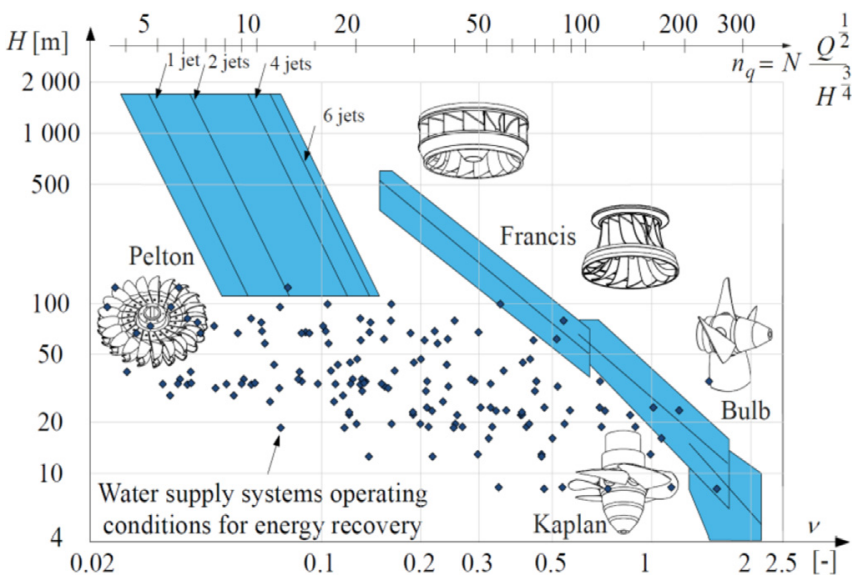

Fig. 2. Comparison between the scope of conventional hydropower turbines and the operating conditions for energy recovery in WSS. Scope of conventional turbines is adapted from Ref. [22].

considers values of the rotational speed $N$ between $500 \mathrm{~min}^{-1}$ and $3000 \mathrm{~min}^{-1}$, and the use of several units in parallel, depending on the discharge.

$n_{\mathrm{q}}=N \frac{Q^{\frac{1}{2}}}{H^{\frac{3}{4}}}$

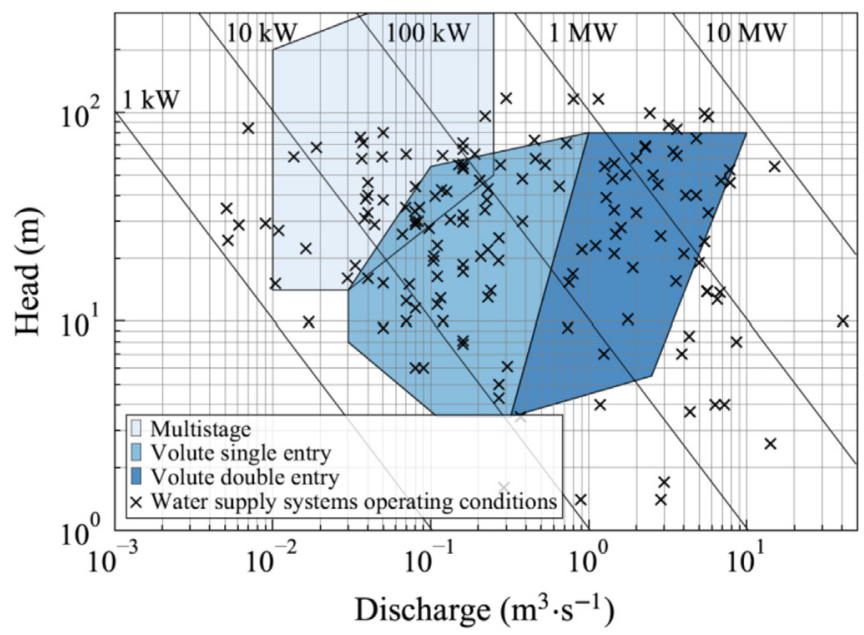

Fig. 3. Comparison between PAT range of operation and potential for energy recovery in WSS. PAT scope of application adapter from Ref. [31].

where $N$ is the rotational speed in $\min ^{-1}, Q$ is the discharge in $\mathrm{m}^{3} \cdot \mathrm{s}^{-1}$, and $H$ is the head in $\mathrm{m}$. Note that $n_{\mathrm{q}}$ is unit dependent.

Pumps running as turbines (PATs ${ }^{1}$ ) are pointed as a costeffective solution for energy recovery in WSS [23]. Other types of turbines suggested for energy recovery in WSS are Pelton turbines operating with a counter-pressure [24], a tubular propeller turbine [25], an inline drag-type turbine [26], a counter-rotating micro turbine [27], a crossflow turbine [28], mini compact standardised Pelton, Francis and Kaplan turbines [29]. Main advantages of PATs are the small capital investment, the immediate availability in a wide range of head and discharge, and the good efficiency at the best efficiency point (BEP) [30]. Indeed, the PATs range of application [31] covers most of the WSS average operating conditions, as illustrated in Fig. 3.

The use of PATs for energy recovery in WSS has been extensively addressed by the research community. The prediction of the complete turbine mode characteristic curves is the most investigated topic in PAT literature. A prediction method based on polynomial regression curves has been proposed in Ref. [32]. The same approach was followed in Ref. [33], though different empirical coefficients have to be recomputed for the new tested PATs. Fecarotta et al. [34] propose a different method based on the turbomachine similarity laws for predicting the turbine mode characteristic curves. Also, the identification of the PATs location in WSS has been investigated for minimizing water losses in the network [35] or maximizing the energy recovered [36]. A real-time controller for PAT simultaneously recover energy and regulate pressure is suggested in Ref. [37]. The economic analysis of a PAT hypothetical hydropower system is analysed for different European countries in Ref. [38].

PATs are characterised by a sharp efficiency decrease if operated with fixed rotational speed and in off-design conditions [39]. This is, when the discharge is smaller or higher than the value at the BEP, the so-called part load and the full load, respectively. A PAT energy recovery system is surely bound to experience off-design operation, as one of WSS main characteristic is the daily variable discharge, as illustrated in Fig. 4. This flow variation is caused by the consumerdriven demand discharge $[40,41]$.

\footnotetext{
${ }^{1}$ In this paper, PATs refer to the plural version of the acronym (pumps running as turbines), while PAT refers to the singular version of the acronym (pump running as turbine).
} 


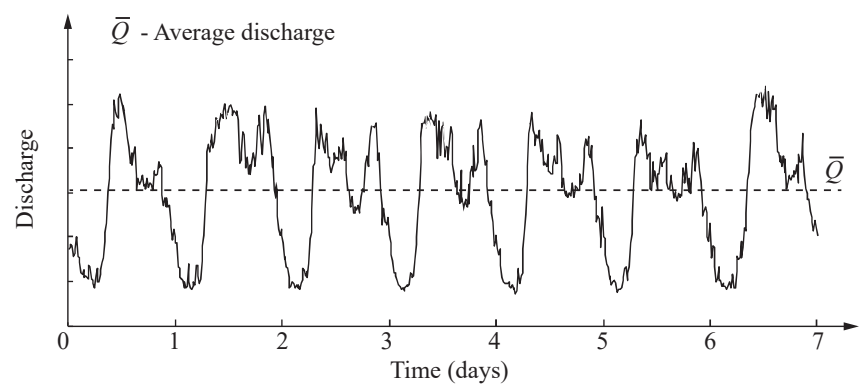

Fig. 4. Typical discharge time history in a water distribution network for one week. The dashed line represents the average discharge. Typically, the maximum discharge is greater by a factor of 3 or 4 than the minimum discharge.

The efficiency decrease in off-design conditions when operating with fixed rotational speed is a result of the absence of a discharge control component (e.g., guide vanes in Francis turbines). When the discharge deviates from the value at the BEP, the impeller blades' leading edge experience flow incidence. This may lead to the flow detachment in the pressure side and suction side, respectively for part load and full load (see Fig. 5). The tip rounding of the blades leading edge is suggested to mitigate this problem $[42,43]$. Moreover, there is a swirling flow at the impeller outlet (i.e., $C_{u \overline{1}} \neq 0$ ) in the same and inverse runner rotation direction, for part load and full load, respectively. Both these occurrences may decrease the PAT efficiency.

Variable speed operation has been pointed out as a control strategy to increase the efficiency and the energy yield under variable flow operation [44], as it allows controlling the inlet flow of the machine. The speed control allows adjusting the velocity triangles at the PAT impeller blades' leading edge, as illustrated in Fig. 5. Such velocity triangle adjustment, similarly to the velocity triangles corresponding to the BEP at the rated speed, reduces the flow incidence at the PAT high pressure section and the swirling flow at the PAT low pressure section. Research findings of PAT variable speed performance are inconsistent. Experimental results in Ref. [45] suggest that the maximum efficiency decreases with increasing rotational speed. These results are contradicted by the results shown in Ref. [17]. Also, the research work in Ref. [46] concludes that variable speed operation does not bring a substantial benefit solely based on the proximity of the discharge-head characteristic curves. Such conclusion contradicts the suggestion in Ref. [44]. Therefore, further research is required on the variable speed operation of pumps in the turbine mode.

The hydropower plants installed in WSS need to maintain the safety and effective level of water supply [47], both in regular (e.g., start-up) and emergency operation (e.g., generator sudden load rejection). The dynamics of the power plant are represented by the Eq. (2), which describes the inertial effect of the rotating masses, and by the four quadrants of operation of the machine. The latter describes the interaction between the parameters of specific hydraulic energy $E=g H$, discharge $Q$, torque $T$, and rotational speed $N$. The four quadrants (Fig. 6 and Table 2) are represented by the non-dimensional factors of rotational speed $n_{E D}$, discharge $Q_{E D}$, and torque $T_{E D}$, defined by Eq. (3).

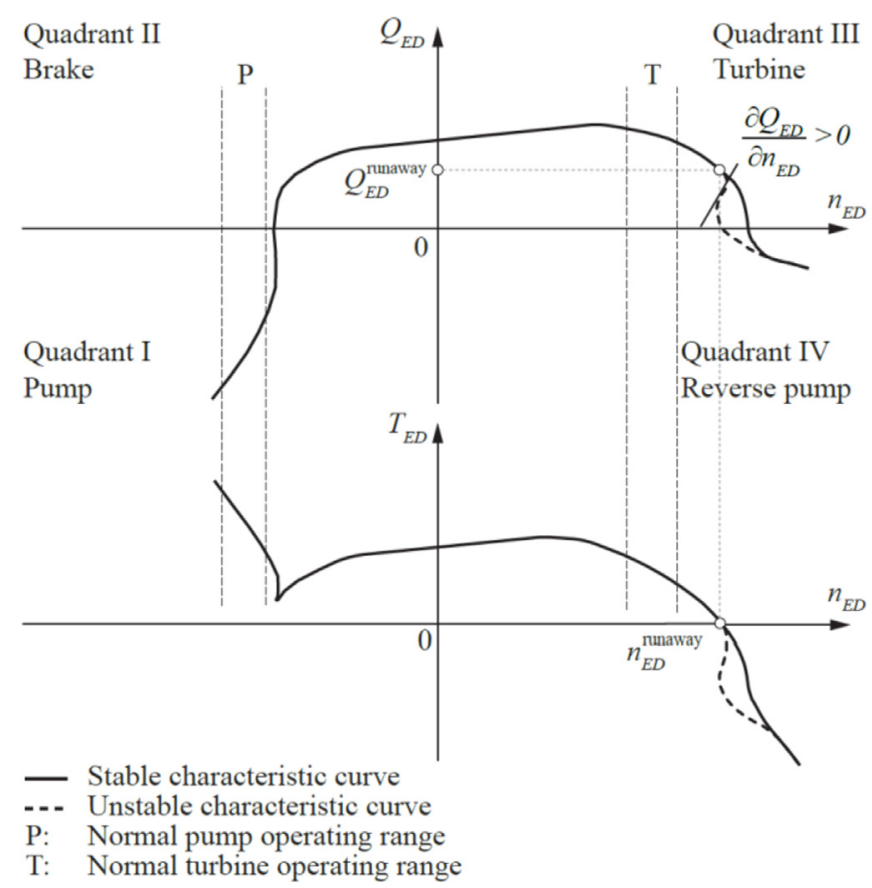

Fig. 6. Identification of the four quadrants operation of a pump.
Part load

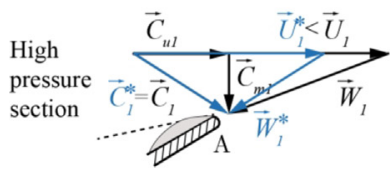

Best Efficiency Point

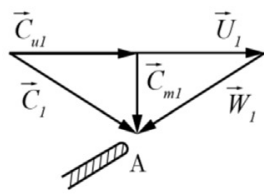

Low
pressure
section

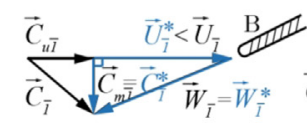

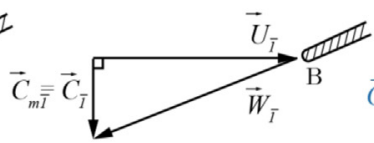

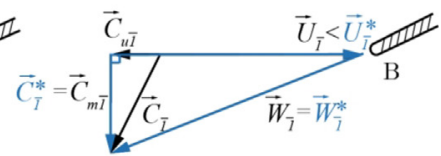

Full load

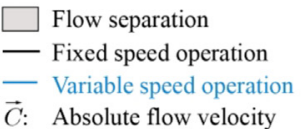

$\begin{array}{ll}\vec{W}: & \text { Relative flow velocity } \\ \vec{U}: & \text { Rotating velocity } \\ \alpha: & \text { Absolute flow velocity angle } \\ \beta: & \text { Relative flow velocity angle }\end{array}$
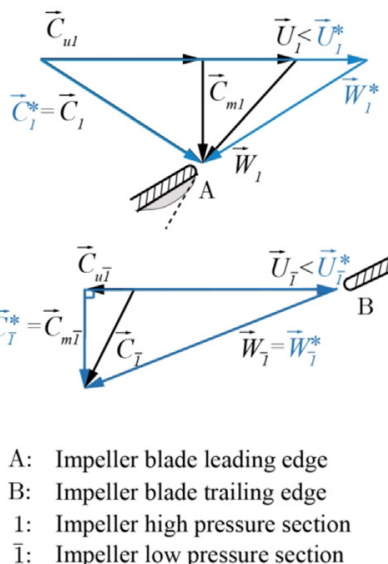

$\vec{C}$ : Absolute flow velocity

$\overline{1}$ : Impeller low pressure section

Fig. 5. Velocity triangles at the high and low pressure sections of the pump impeller for the part load, best efficiency point and full load operating points. 
Table 2

Quadrants and operating modes definitions used for the experimental investigation.

\begin{tabular}{llllll}
\hline ID & Quadrant name & $Q$ & $N$ & $T$ & Mode \\
\hline 1 & Pump & - & - & + & Pump \\
$1 / 2$ & - & 0 & - & + & Zero discharge \\
2 & Brake & + & - & + & Pump-brake \\
3 & Turbine & + & + & + & Turbine \\
& & + & + & 0 & Runaway \\
& & + & + & - & Turbine-brake \\
$3 / 4$ & - & 0 & + & - & Zero discharge \\
4 & Reverse pump & - & + & - & Reverse rotation pump \\
\hline
\end{tabular}

$J \frac{d \omega}{d t}=T+T_{\mathrm{el}}$

$n_{E D}=\frac{n D}{\sqrt{E}} ; Q_{E D}=\frac{Q}{D^{2} \sqrt{E}} ; T_{E D}=\frac{T}{\rho D^{3} E}$

where $J$ is the pump moment of inertia, $\omega$ is the radial speed, $T_{\mathrm{el}}$ the electric resisting load, $n_{E D}, Q_{E D}$, and $T_{E D}$ are the factors of rotational speed, discharge and torque, respectively, $n$ is the rotational speed, $D$ is the reference diameter, and $\rho$ is the water density.

The extended operation of pump-turbines (i.e., custom-made Francis reversible pump-turbines used in large hydropower plants) is oftentimes described by an unstable characteristic curve, near the turbine runaway, defined by $\partial Q_{E D} / \partial n_{E D}>0$ (see Fig. 6). This is frequently observed in low specific speed reversible pumpturbines [48]. This unstable feature may induce the constant shift between the turbine and the reverse pump modes, creating vibration and noise [49]. PATs are also likely to experience this unstable performance, as pump-turbines impellers are mostly designed for pumping mode. Yet, to the authors' knowledge, no research has been conducted about the existence of the instability near the runaway operating point of pumps running as turbines. Further research is required on this topic.

This research paper aims at gathering the stationary performance data required for the development of the technical specifications of variable speed PAT systems for energy recovery in WSS. These stationary performance data is collected for three end-suction single-stage centrifugal pumps with different $n_{\mathrm{q}}$ values. The testing of the turbine mode aims at understanding if the variable speed control allows increasing the efficiency of the PAT in the part load and the full load of operation, and consequently the power yield. The testing of the extended operation mode aims at verifying if the PATs feature the unstable characteristic curve near the runaway operating point. For this purpose, a new experimental facility is assembled for testing reaction hydraulic machines, both in pumping and generating mode. The description of the test-rig and the experimental procedure are outlined in Section 2. The collected experimental results of the pump, turbine and extended modes of operation are presented in Section 3. These results are later discussed in Section 4, focusing on the variable speed characteristics in the turbine mode and in the extended operation mode. Finally, the
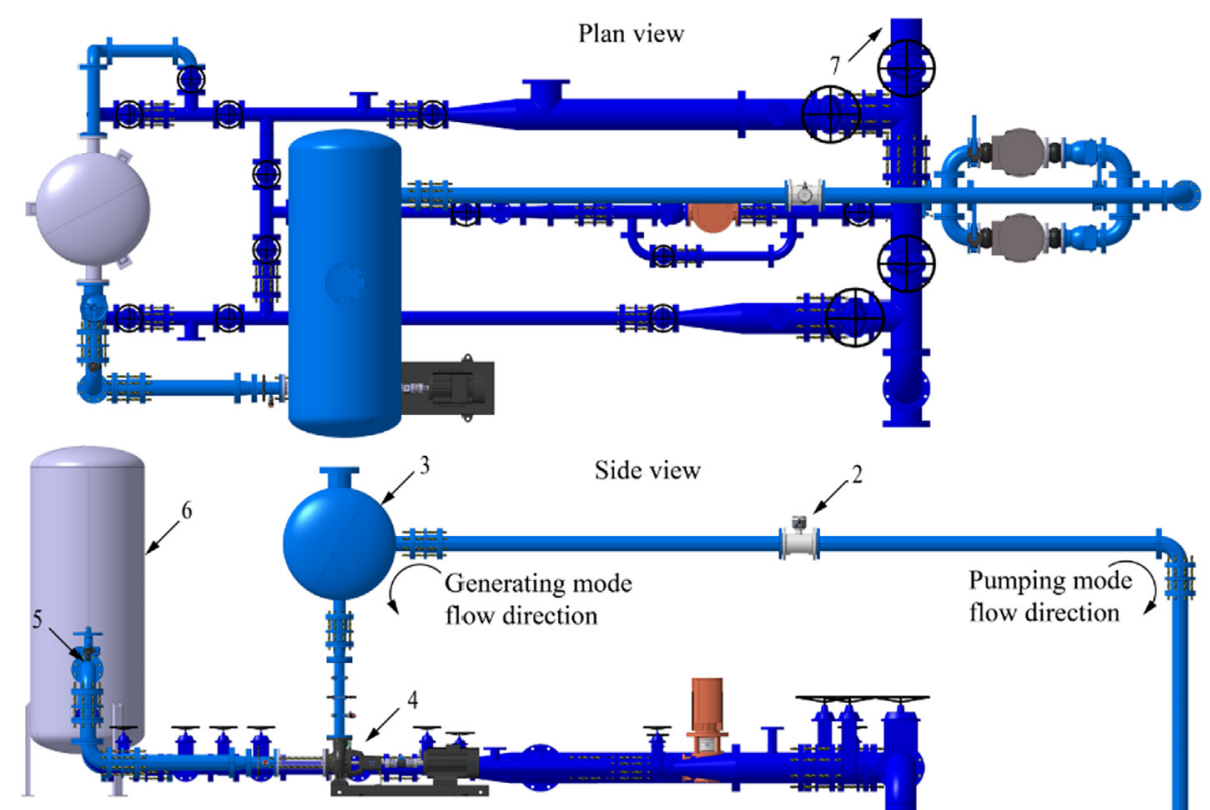

1. Supply pumps

2. Flow meter

3 . High pressure air vessel

4. Test-platform

5. Temperature sensor

6. Low pressure air vessel

7. Connection to storage tank

8. Manifolds for pressure measurement

9. Plexiglas pipe

10. Torque and speed sensors

11. PAT impeller

12. Induction generator

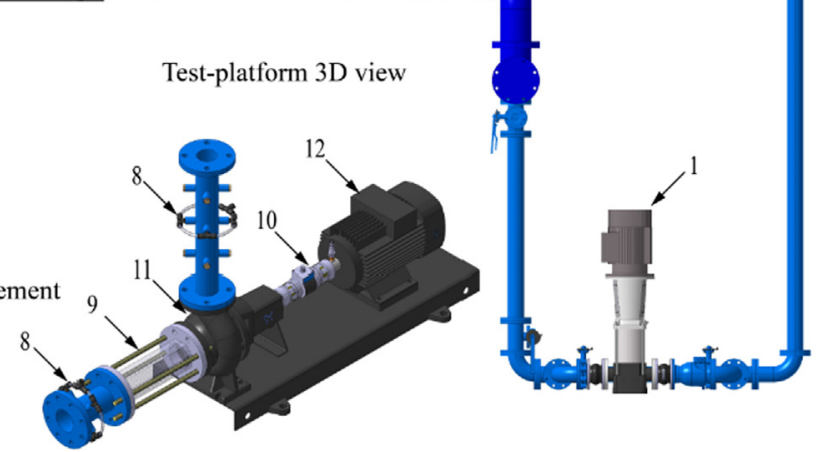

Fig. 7. Test-rig overview. 
Table 3

Measurement equipment characteristics.

\begin{tabular}{|c|c|c|c|c|}
\hline ID & Measurement & Range & Unit & Accuracy \\
\hline$Q$ & Discharge & $0-0.04$ & $\mathrm{~m}^{3} \cdot \mathrm{s}^{-1}$ & $0.40 \%$ of $\operatorname{span}\left( \pm 1.6 \times 10^{-4} \mathrm{~m}^{3} \cdot \mathrm{s}^{-1}\right)$ \\
\hline$\Delta p_{1}$ & Differential pressure 1 & $0-7.5$ & bar & $0.14 \%$ of span $( \pm 0.011$ bar $)$ \\
\hline$\Delta p_{2}$ & Differential pressure 2 & $-0.2-2.1$ & bar & $0.14 \%$ of $\operatorname{span}( \pm 0.003$ bar $)$ \\
\hline$T$ & Torque & $-50-50$ & $\mathrm{~N} \cdot \mathrm{m}$ & $0.30 \%$ of $\max ( \pm 0.15 \mathrm{~N} \cdot \mathrm{m})$ \\
\hline$N$ & Rotational speed & $0-50$ & $\mathrm{~s}^{-1}$ & $0.20 \%$ of $\operatorname{span}\left( \pm 0.1 \mathrm{~s}^{-1}\right)$ \\
\hline$\theta$ & Temperature & $0-100$ & ${ }^{\circ} \mathrm{C}$ & $0.30 \%$ of $\operatorname{span}\left( \pm 0.3^{\circ} \mathrm{C}\right)$ \\
\hline$P_{\text {sup }}$ & Active electric power & $-10-10$ & $\mathrm{~kW}$ & $0.50 \%$ of $\max ( \pm 0.05 \mathrm{~kW})$ \\
\hline$Q_{\text {sup }}$ & Reactive electric power & $-10-10$ & $\mathrm{kVAr}$ & $2.00 \%$ of $\max ( \pm 0.2 \mathrm{kVAr})$ \\
\hline
\end{tabular}

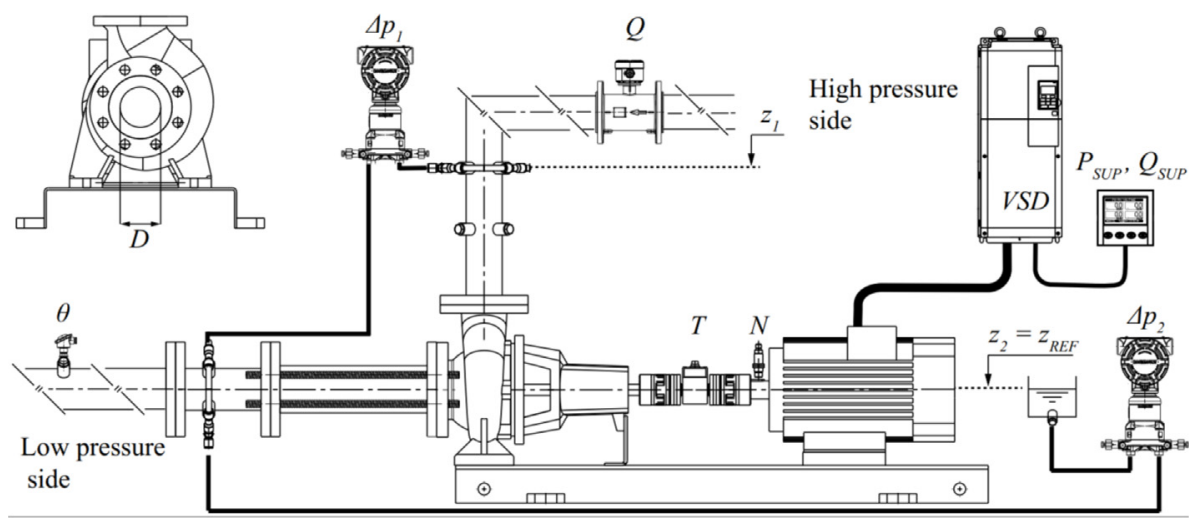

Fig. 8. Measurement setup of the test-rig.

main conclusions and future perspectives are drawn in Section 5.

\section{Experimental setup}

\subsection{Test-rig and measurement setup}

The experimental investigation is carried out in the new test-rig of the Laboratory of Hydraulics and Environment at Instituto Superior Técnico, Universidade de Lisboa. The test-rig consists of a reversible closed-loop steel-pipe facility (Fig. 7). Two feed pumps, installed at a lower level, provide the required hydraulic power to the PATs. Each pump, with a rated power of $15 \mathrm{~kW}$, delivers a maximum discharge and pressure of $241 \cdot \mathrm{s}^{-1}$ and $8 \mathrm{bar}$, respectively. The discharge supplied to the test-platform is controlled using two variable speed drives (VSD). The feed pumps are provided with a by-pass for flow circulation in both directions. The maximum installed pumping power allows performing experimental tests up to $40 \mathrm{l} \cdot \mathrm{s}^{-1}$.

A $1 \mathrm{~m}^{3}$ pressure vessel, installed at the PAT high pressure side, provides flow stabilisation and a uniform velocity profile at the PAT inlet. The test-rig allows investigating differently sized hydraulic machines. The PATs rotational speed is fully controlled between $300 \mathrm{~min}^{-1}$ and $3000 \mathrm{~min}^{-1}$ using a $15 \mathrm{~kW}$ VSD. This VSD controls the PAT in the four quadrants. The original induction motors are

Table 4

Pump mode rated characteristics of the selected pumps.

\begin{tabular}{|c|c|c|c|c|c|c|}
\hline \multirow[t]{2}{*}{ Pump ID } & $Q_{R}$ & $H_{\mathrm{R}}$ & $N_{\mathrm{R}}$ & $P_{\mathrm{R}}$ & $n_{\mathrm{q}}$ & $D$ \\
\hline & $\left(\mathrm{m}^{3} \cdot \mathrm{s}^{-1}\right)$ & $(\mathrm{m})$ & $\left(\min ^{-1}\right)$ & $(\mathrm{kW})$ & $(\mathrm{SI})$ & $(\mathrm{m})$ \\
\hline NK $40-160 / 158$ & 0.0109 & 31.1 & 2910 & 5.0 & 23.1 & 0.065 \\
\hline NK $40-125 / 127$ & 0.0130 & 16.2 & 2900 & 2.8 & 41.0 & 0.065 \\
\hline NK $65-125 / 127$ & 0.0298 & 14.6 & 2910 & 5.5 & 67.3 & 0.080 \\
\hline
\end{tabular}

used as asynchronous generators. The test-platform is equipped with a $350 \mathrm{~mm}$ transparent Plexiglas pipe for flow visualisation at the low pressure side of the PATs.

A second $1 \mathrm{~m}^{3}$ pressure vessel, installed at the PAT low pressure side, is used to create different backpressure levels. Both vessels are equipped with valves for admission and release of compressed air. The low pressure vessel and the feed pumps are connected by three pipes installed in parallel. Several isolation valves allow the operation of these pipes in different configurations. The test-rig is filled with water from a $40 \mathrm{~m}^{3}$ storage tank.

The test-rig is equipped with instrumentation for measuring the PATs hydraulic, mechanical and electrical parameters. The characteristics and location of the measurement equipment are shown in Table 3 and Fig. 8, respectively. Measurements are simultaneously acquired using a data acquisition hardware (NI cDAQ9178) from National Instruments ${ }^{\mathrm{TM}}$, connected to a computer. The acquisition hardware is equipped for both voltage (NI 9205) and current (NI 9203) analogue inputs. Moreover, it also generates voltage analogue outputs (NI 9269) for controlling the three VSD. The data acquisition and control software [50] controls the three VSD, as well as acquires, processes, logs and visualises the measurement data in real-time.

\subsection{Experimental tests performed}

The experimental investigation is performed in three singlestage end-suction closed-impeller centrifugal pumps with different $n_{\mathrm{q}}$ values. The rated characteristics in pumping mode are outlined in Table 4, namely: the discharge $Q_{R}$, the head $H_{R}$, the rotational speed $N_{\mathrm{R}}$, the shaft power $P_{\mathrm{R}}$, the unit specific speed $n_{\mathrm{q}}$, and the reference diameter $D$, which is considered as the value at the volute low pressure section (see Fig. 8).

The specific hydraulic energy $E$ is defined by: 

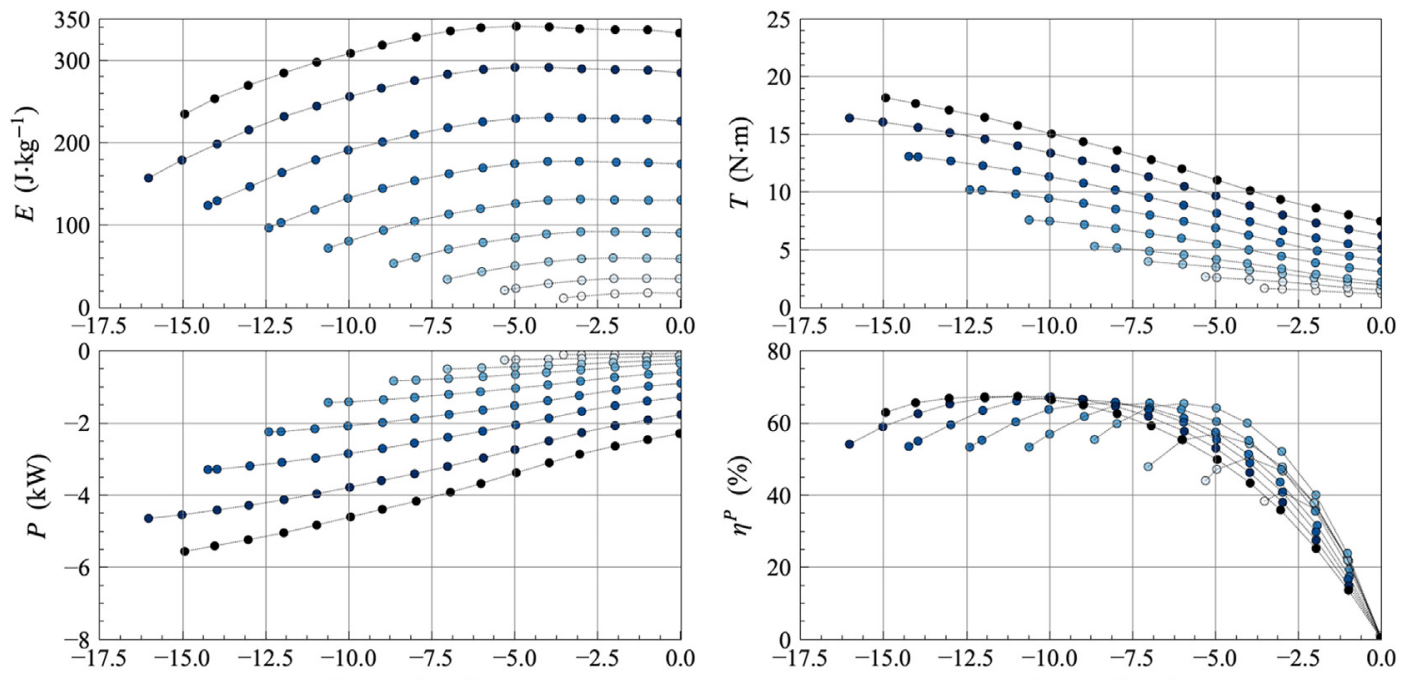

$10^{-3} \times Q\left(\mathrm{~m}^{3} \cdot \mathrm{s}^{-1}\right)$

$10^{-3} \times Q\left(\mathrm{~m}^{3} \cdot \mathrm{s}^{-1}\right)$

$\circ 600 \mathrm{~min}^{-1} \circ 900 \mathrm{~min}^{-1} \odot 1200 \mathrm{~min}^{-1} \cdot 1500 \mathrm{~min}^{-1} \cdot 1800 \mathrm{~min}^{-1} \bullet 2100 \mathrm{~min}^{-1} \cdot 2400 \mathrm{~min}^{-1} \bullet 2700 \mathrm{~min}^{-1} \cdot 2920 \mathrm{~min}^{-1}$

Fig. 9. Experimental results in pumping mode of the $n_{\mathrm{q}}=23.1$ pump.
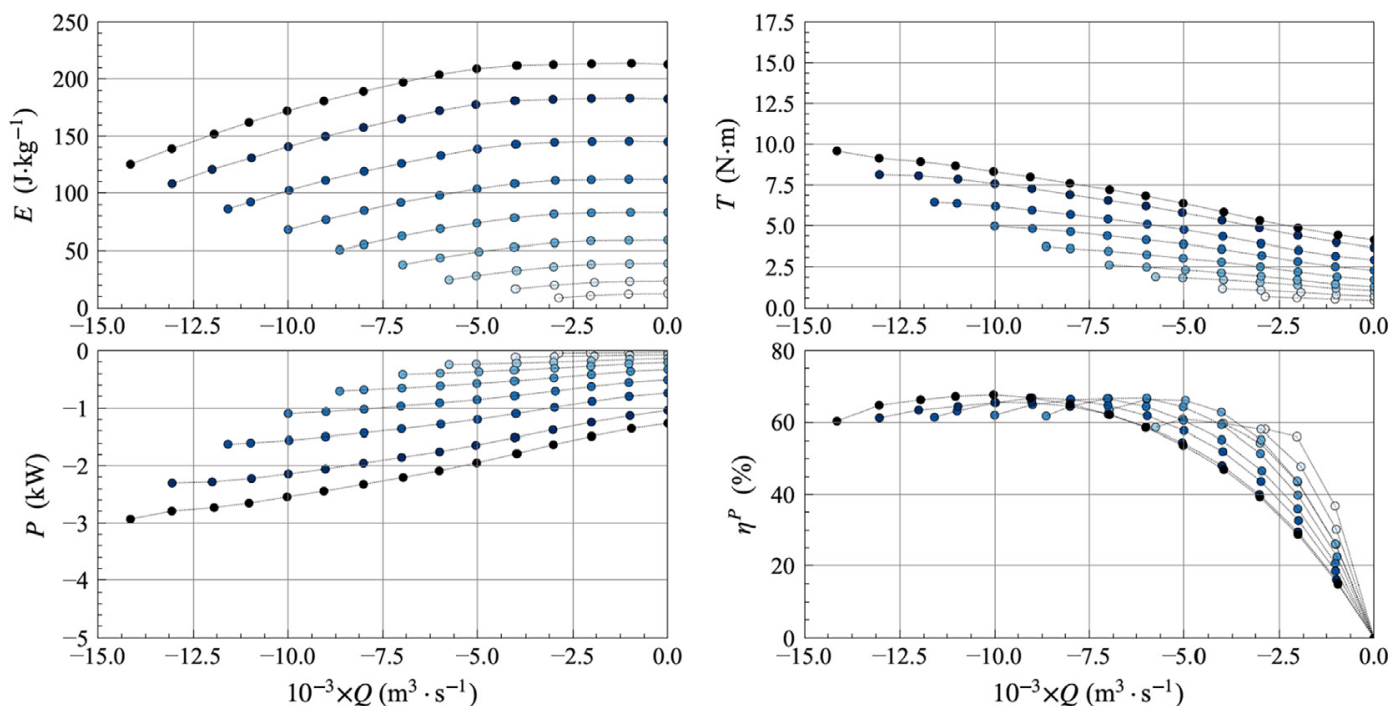

$\circ 600 \mathrm{~min}^{-1} \circ 900 \mathrm{~min}^{-1} \circ 1200 \mathrm{~min}^{-1} \cdot 1500 \mathrm{~min}^{-1} \cdot 1800 \mathrm{~min}^{-1} \cdot 2100 \mathrm{~min}^{-1} \cdot 2400 \mathrm{~min}^{-1} \cdot 2700 \mathrm{~min}^{-1} \cdot 2920 \mathrm{~min}^{-1}$

Fig. 10. Experimental results in pumping mode of the $n_{\mathrm{q}}=41.0$ pump.

$E=\frac{p_{\mathrm{abs}, 1}-p_{\mathrm{abs}, 2}}{\bar{\rho}}+\frac{C_{1}^{2}-C_{2}^{2}}{2}+g\left(z_{1}-z_{2}\right)$

where $p_{\mathrm{abs}}$ is the absolute pressure, $C$ is the flow velocity, $g$ is the gravity acceleration, $z$ is the elevation, and $\bar{\rho}=\left(\rho_{1}-\rho_{2}\right) / 2$ is the average water density, which is a function of the pressure and temperature $\theta$ [51]. Subscripts 1 and 2 refer to the high and low pressure measurement sections, respectively. According to the measurement setup of Fig. 8, $E$ is determined based by [51]:

$E=\frac{\Delta p_{1}}{\rho_{2}}+\frac{C_{1}^{2}-C_{2}^{2}}{2}$

The hydraulic and mechanical shaft power, $P_{\mathrm{h}}$ and $P$, are given by Eqs. (6) and (7), respectively. The active and reactive electric power, $P_{\text {sup }}$ and $Q_{\text {sup }}$, are directly measured using a digital power analyser.

$P_{\mathrm{h}}=\rho_{1} \mathrm{QE}$

$P=2 \pi n T$

where $n$ is the rotational speed ( $n$ and $N$ refer to the rotational speed in $\mathrm{Hz}$ and $\mathrm{min}^{-1}$, respectively).

Finally, the mechanical, electrical and global efficiency $\eta, \eta_{\mathrm{el}}$ and $\eta_{\mathrm{g}}$, respectively, are given by Eq. (8). Superscripts $P$ and $T$ refer to the pump and the turbine mode, respectively. The torque sensor is assembled at the connection of the PAT shaft and the induction generator. The digital power analyser is installed between the electric grid and the regenerative VSD. Therefore, the mechanical 

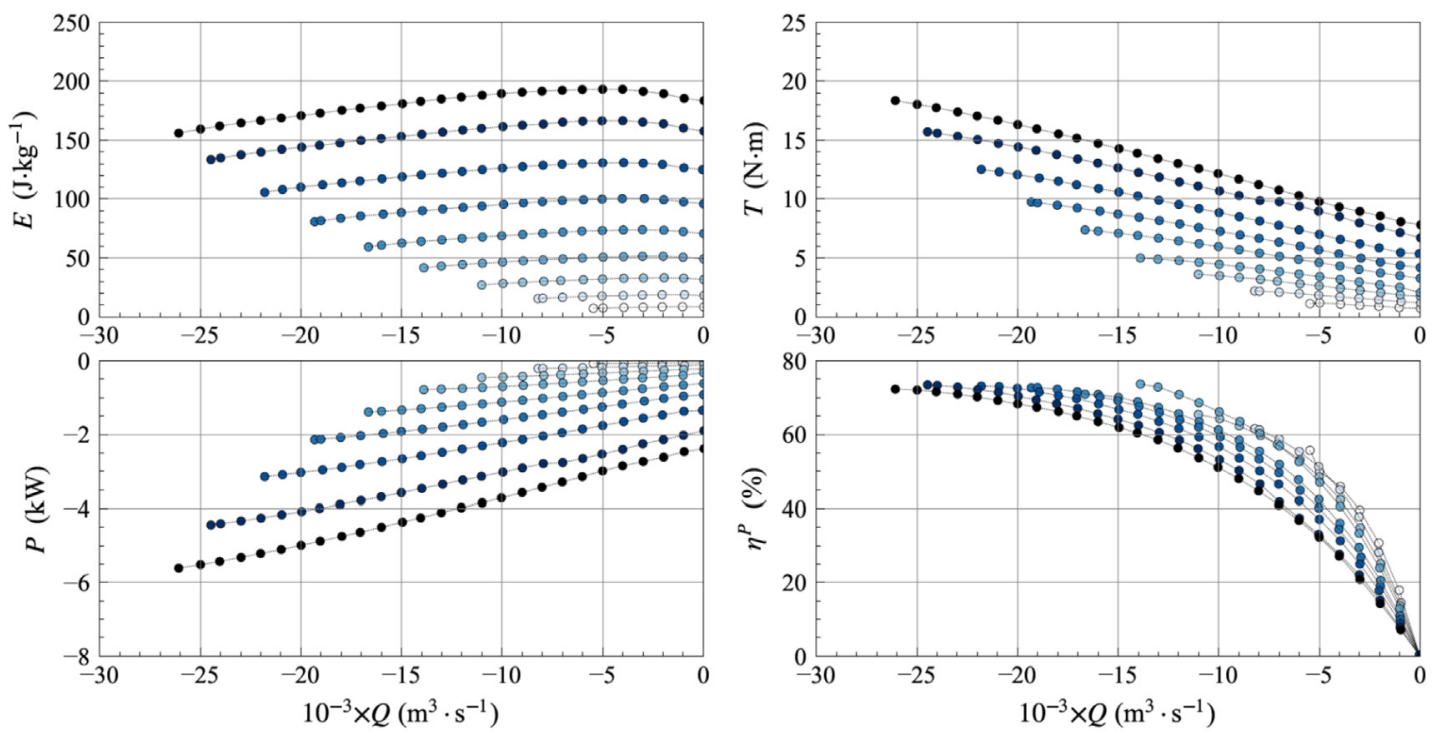

$\circ 600 \mathrm{~min}^{-1} \circ 900 \mathrm{~min}^{-1} \odot 1200 \mathrm{~min}^{-1} \cdot 1500 \mathrm{~min}^{-1} \cdot 1800 \mathrm{~min}^{-1} \cdot 2100 \mathrm{~min}^{-1} \cdot 2400 \mathrm{~min}^{-1} \cdot 2700 \mathrm{~min}^{-1} \cdot 2920 \mathrm{~min}^{-1}$

Fig. 11. Experimental results in pumping mode of the $n_{\mathrm{q}}=67.3$ pump.

Table 5

BEP measurements of the pump mode for $N$ values between $1500 \mathrm{~min}^{-1}$ and $3000 \mathrm{~min}^{-1}$. Values inside parentheses indicate the total relative errors.

\begin{tabular}{|c|c|c|c|c|c|c|c|c|c|}
\hline Pump ID & $N\left(\min ^{-1}\right)$ & $Q\left(1 \cdot \mathrm{s}^{-1}\right)$ & $E\left(\mathrm{~J} \cdot \mathrm{kg}^{-1}\right)$ & $T(\mathrm{~N} \cdot \mathrm{m})$ & $P(\mathrm{~kW})$ & $\eta^{\mathrm{P}}(\%)$ & $n_{E D}(-)$ & $Q_{E D}(-)$ & $T_{E D}(-)$ \\
\hline \multirow[t]{6}{*}{$n_{\mathrm{q}}=23.1$} & $-1500( \pm 0.4 \%)$ & $-6.0( \pm 2.7 \%)$ & $19.0( \pm 1.5 \%)$ & & $-0.7( \pm 3.3 \%)$ & $f(I+$. & $-0.183( \pm 1.4 \%)$ & $-0.159( \pm 3.0 \%)$ & $0.211( \pm 3.5 \%)$ \\
\hline & $-1800( \pm 0.3 \%)$ & $-7.0( \pm 2.3 \%)$ & $113.3( \pm 0.9 \%)$ & $6.4( \pm 2.3 \%)$ & $-1.2( \pm 2.4 \%)$ & $65.5( \pm 3.4 \%)$ & $-0.183( \pm 1.0 \%)$ & $-0.155( \pm 2.5 \%)$ & $0.206( \pm 2.5 \%)$ \\
\hline & $-2099( \pm 0.3 \%)$ & $-8.0( \pm 2.0 \%)$ & $154.0( \pm 0.7 \%)$ & $8.5( \pm 1.8 \%)$ & $-1.9( \pm 1.8 \%)$ & $65.7( \pm 2.8 \%)$ & $-0.183( \pm 0.7 \%)$ & $-0.153( \pm 2.1 \%)$ & $0.202( \pm 1.9 \%)$ \\
\hline & $-2398( \pm 0.3 \%)$ & $-10.0( \pm 1.6 \%)$ & $191.0( \pm 0.6 \%)$ & $11.3( \pm 1.3 \%)$ & $-2.8( \pm 1.3 \%)$ & $67.0( \pm 2.2 \%)$ & $-0.188( \pm 0.6 \%)$ & $-0.172( \pm 1.7 \%)$ & $0.217( \pm 1.4 \%)$ \\
\hline & $-2700( \pm 0.2 \%)$ & $-10.0( \pm 1.6 \%)$ & $256.0( \pm 0.4 \%)$ & $13.4( \pm 1.1 \%)$ & $-3.8( \pm 1.1 \%)$ & $67.3( \pm 2.0 \%)$ & $-0.183( \pm 0.5 \%)$ & $-0.147( \pm 1.7 \%)$ & $0.191( \pm 1.2 \%)$ \\
\hline & $-2922( \pm 0.2 \%)$ & $-11.0( \pm 1.5 \%)$ & $297.6( \pm 0.4 \%)$ & $15.8( \pm 1.0 \%)$ & $-4.8( \pm 1.0 \%)$ & $67.4( \pm 1.8 \%)$ & $-0.183( \pm 0.4 \%)$ & $-0.150( \pm 1.5 \%)$ & $0.194( \pm 1.0 \%)$ \\
\hline \multirow[t]{6}{*}{$n_{\mathrm{q}}=41.0$} & $-1500( \pm 0.4 \%)$ & $-6.0( \pm 2.7 \%)$ & $43.8( \pm 2.4 \%)$ & $2.5( \pm 6.0 \%)$ & $-0.4( \pm 6.0 \%)$ & $66.4( \pm 7.0 \%)$ & $-0.246( \pm 2.4 \%)$ & $-0.214( \pm 3.6 \%)$ & $0.209( \pm 6.4 \%)$ \\
\hline & $-1800( \pm 0.3 \%)$ & $-6.0( \pm 2.7 \%)$ & $68.8( \pm 1.5 \%)$ & $3.3( \pm 4.6 \%)$ & $-0.6( \pm 4.6 \%)$ & $66.7( \pm 5.5 \%)$ & $-0.235( \pm 1.6 \%)$ & $-0.171( \pm 3.1 \%)$ & $0.173( \pm 4.8 \%)$ \\
\hline & $-2099( \pm 0.3 \%)$ & $-7.0( \pm 2.3 \%)$ & $91.9( \pm 1.2 \%)$ & $4.4( \pm 3.4 \%)$ & $-1.0( \pm 3.4 \%)$ & $66.6( \pm 4.3 \%)$ & $-0.237( \pm 1.2 \%)$ & $-0.173( \pm 2.6 \%)$ & $0.175( \pm 3.6 \%)$ \\
\hline & $-2400( \pm 0.2 \%)$ & $-9.0( \pm 1.8 \%)$ & $111.2( \pm 1.0 \%)$ & $6.0( \pm 2.5 \%)$ & $-1.5( \pm 2.5 \%)$ & $66.8( \pm 3.2 \%)$ & $-0.247( \pm 1.0 \%)$ & $-0.202( \pm 2.0 \%)$ & $0.195( \pm 2.7 \%)$ \\
\hline & $-2700( \pm 0.2 \%)$ & $-10.0( \pm 1.6 \%)$ & $140.8( \pm 0.8 \%)$ & $7.6( \pm 2.0 \%)$ & $-2.1( \pm 2.0 \%)$ & $65.6( \pm 2.7 \%)$ & $-0.247( \pm 0.8 \%)$ & $-0.199( \pm 1.8 \%)$ & $0.196( \pm 2.1 \%)$ \\
\hline & $-2918( \pm 0.2 \%)$ & $-10.0( \pm 1.6 \%)$ & $172.1( \pm 0.6 \%)$ & $8.3( \pm 1.8 \%)$ & $-2.5( \pm 1.8 \%)$ & $67.7( \pm 2.5 \%)$ & $-0.241( \pm 0.7 \%)$ & $-0.181( \pm 1.7 \%)$ & $0.177( \pm 1.9 \%)$ \\
\hline \multirow[t]{6}{*}{$n_{\mathrm{q}}=67.3$} & $-1499( \pm 0.4 \%)$ & $-13.9( \pm 1.2 \%)$ & $41.6( \pm 2.5 \%)$ & $5.0( \pm 3.0 \%)$ & $-0.8( \pm 3.0 \%)$ & $73.7( \pm 4.1 \%)$ & $-0.310( \pm 2.6 \%)$ & $-0.337( \pm 2.8 \%)$ & $0.235( \pm 3.9 \%)$ \\
\hline & $-1799( \pm 0.3 \%)$ & $-16.6( \pm 1.0 \%)$ & $59.3( \pm 1.8 \%)$ & $7.4( \pm 2.0 \%)$ & $-1.4( \pm 2.1 \%)$ & $70.9( \pm 2.9 \%)$ & $-0.312( \pm 1.8 \%)$ & $-0.338( \pm 2.0 \%)$ & $0.243( \pm 2.7 \%)$ \\
\hline & $-2099( \pm 0.3 \%)$ & $-19.3( \pm 0.8 \%)$ & $80.7( \pm 1.3 \%)$ & $9.7( \pm 1.5 \%)$ & $-2.1( \pm 1.6 \%)$ & $72.7( \pm 2.2 \%)$ & $-0.312( \pm 1.3 \%)$ & $-0.336( \pm 1.5 \%)$ & $0.236( \pm 2.0 \%)$ \\
\hline & $-2399( \pm 0.3 \%)$ & $-21.8( \pm 0.7 \%)$ & $105.6( \pm 1.0 \%)$ & $12.5( \pm 1.2 \%)$ & $-3.1( \pm 1.2 \%)$ & $73.1( \pm 1.7 \%)$ & $-0.311( \pm 1.0 \%)$ & $-0.331( \pm 1.2 \%)$ & $0.232( \pm 1.6 \%)$ \\
\hline & $-2699( \pm 0.2 \%)$ & $-24.5( \pm 0.7 \%)$ & $133.5( \pm 0.8 \%)$ & $15.7( \pm 1.0 \%)$ & $-4.4( \pm 1.0 \%)$ & $73.5( \pm 1.4 \%)^{*}$ & $-0.312( \pm 0.8 \%)$ & $-0.331( \pm 1.0 \%)$ & $0.230( \pm 1.2 \%)$ \\
\hline & $-2918( \pm 0.2 \%)$ & $-26.1( \pm 0.6 \%)$ & $155.9( \pm 0.7 \%)$ & $18.4( \pm 0.8 \%)$ & $-5.6( \pm 0.8 \%)$ & $72.3( \pm 1.2 \%)^{*}$ & $-0.312( \pm 0.7 \%)$ & $-0.326( \pm 0.9 \%)$ & $0.230( \pm 1.1 \%)$ \\
\hline
\end{tabular}

${ }^{*}$ Maximum efficiency not measured due to discharge limitation in the test-rig.
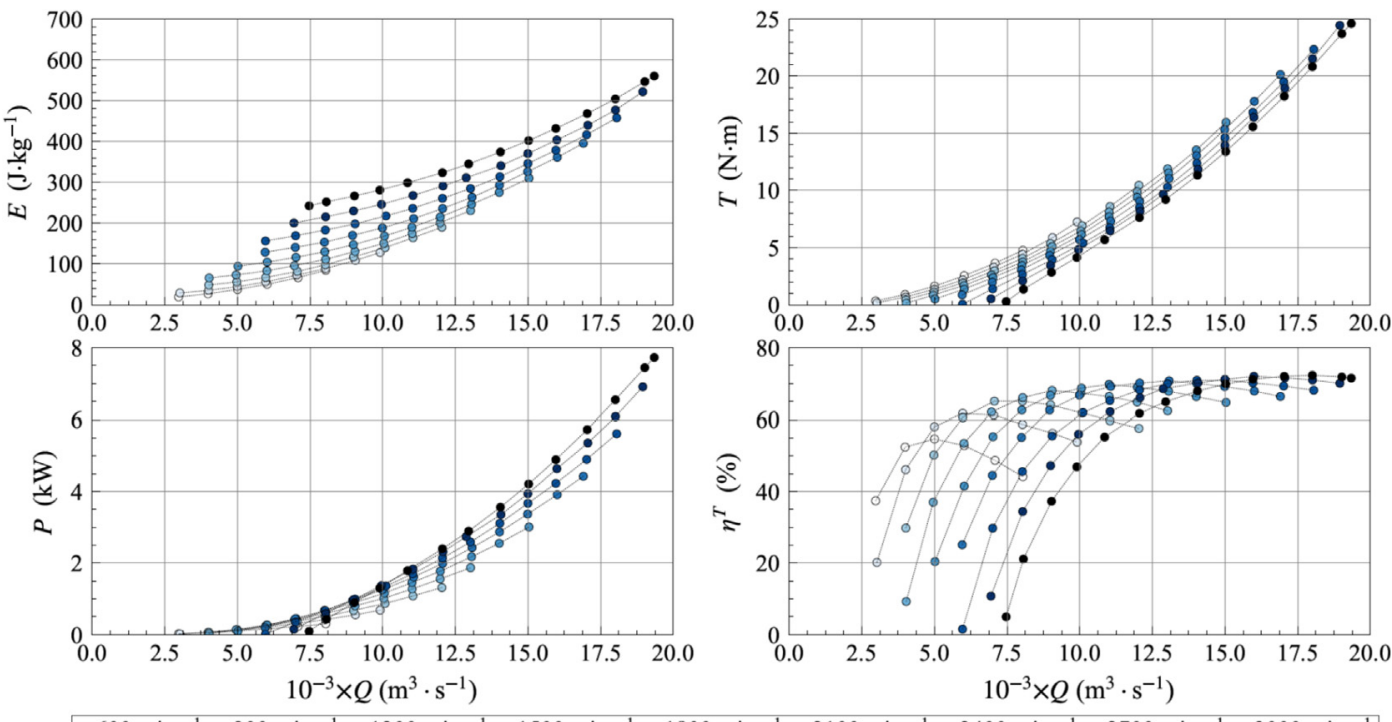

○ $600 \mathrm{~min}^{-1} \circ 900 \mathrm{~min}^{-1} \circ 1200 \mathrm{~min}^{-1} \cdot 1500 \mathrm{~min}^{-1} \cdot 1800 \mathrm{~min}^{-1} \cdot 2100 \mathrm{~min}^{-1} \cdot 2400 \mathrm{~min}^{-1} \cdot 2700 \mathrm{~min}^{-1} \cdot 3000 \mathrm{~min}^{-1}$

Fig. 12. Experimental results in generating mode of the $n_{\mathrm{q}}=23.1$ PAT. 

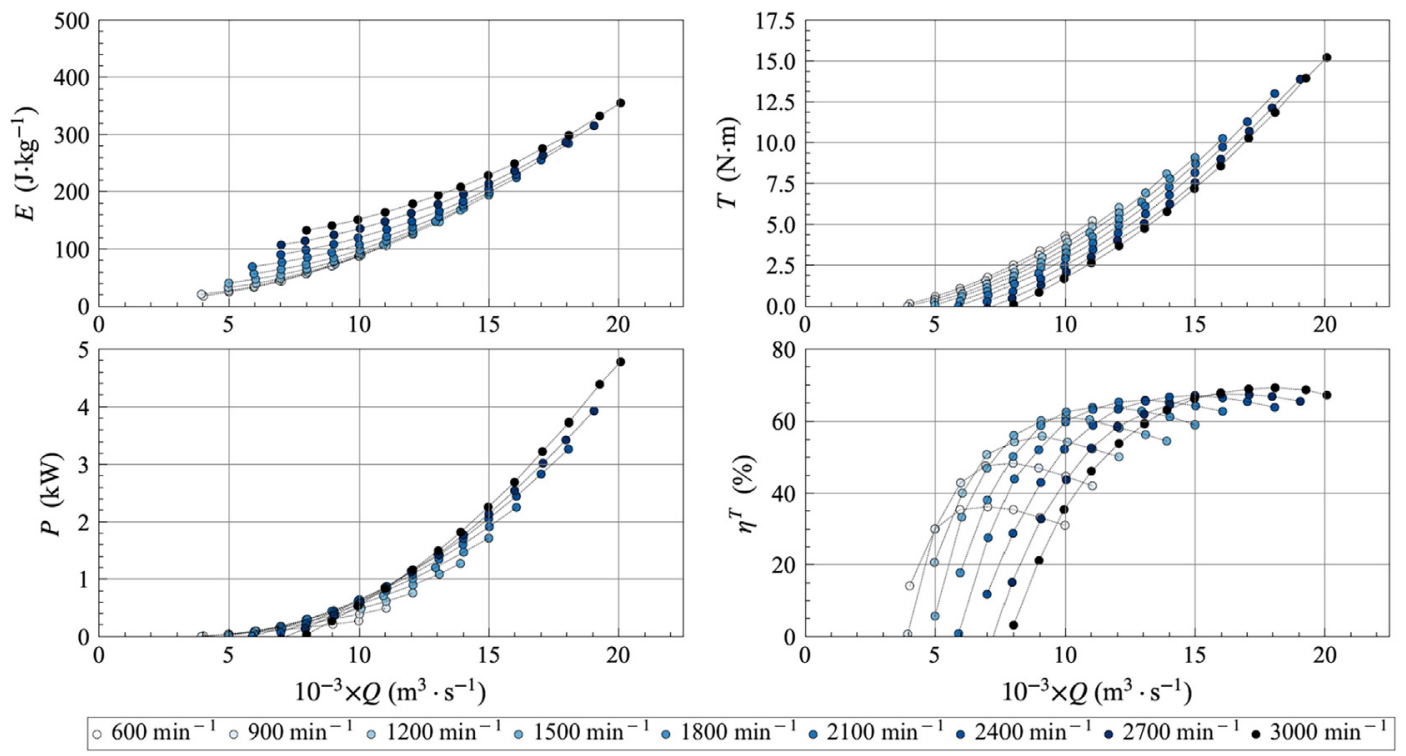

Fig. 13. Experimental results in generating mode of the $n_{\mathrm{q}}=41.0$ PAT.
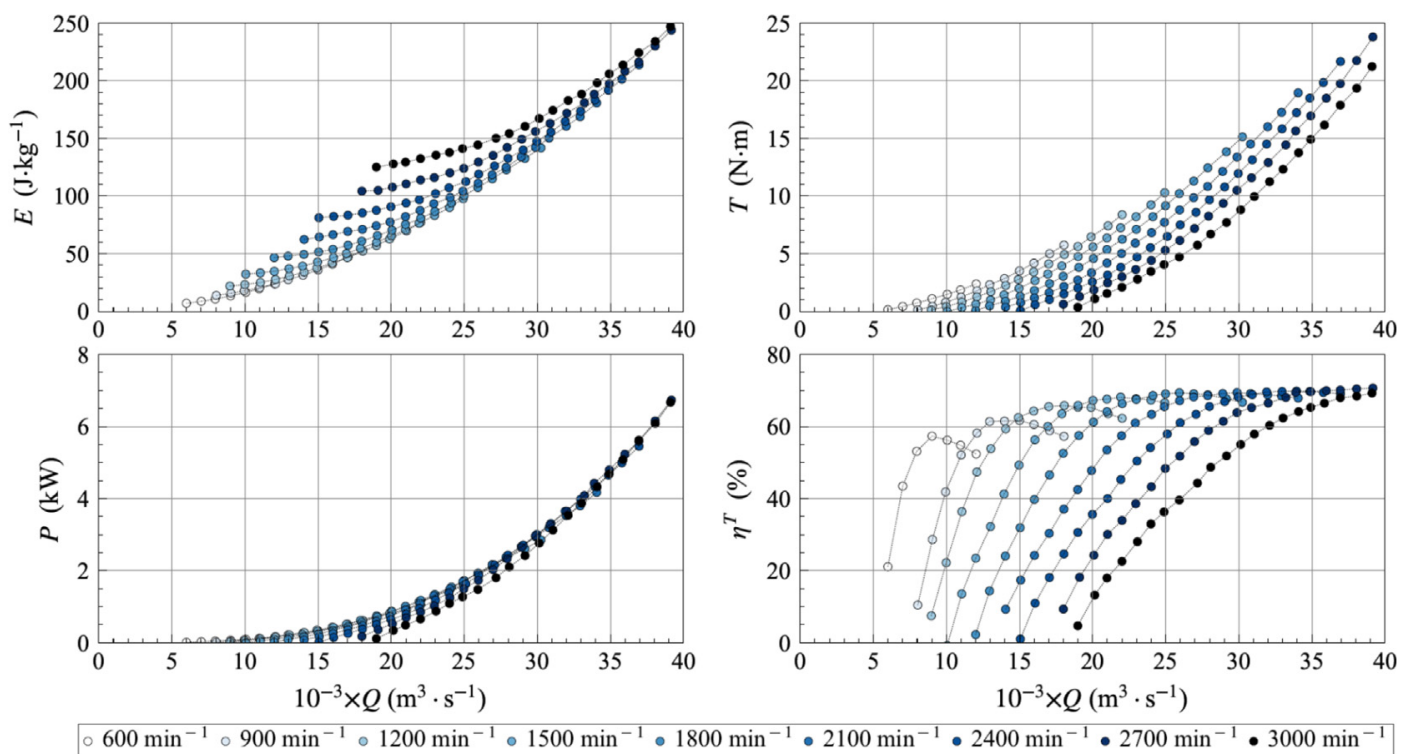

Fig. 14. Experimental results in generating mode of the $n_{\mathrm{q}}=67.3$ PAT.

Table 6

Maximum efficiency values measured in pump and turbine mode.

\begin{tabular}{lllll}
\hline Pump ID & $n_{\mathrm{q}}(\mathrm{SI})$ & $\eta_{\max }^{\mathrm{P}}(\%)$ & $\eta_{\max }^{\mathrm{T}}(\%)$ & $\Delta \eta_{\max }(\%)$ \\
\hline NK 40 - 160/158 & 23.1 & 67.4 & 72.3 & $4.9 \%$ \\
NK 40 - 125/127 & 41.0 & 67.7 & 69.2 & $1.5 \%$ \\
NK 65 - 125/127 & 67.3 & 73.5 & $70.7^{*}$ & $-2.8 \%$ \\
\hline
\end{tabular}

* Maximum efficiency not measured in the test-rig

efficiency, $\eta$, takes into account the power losses associated with leakage flow, disk friction, specific energy losses in the volute and impeller and bearing and seals friction [52]. The electric efficiency, $\eta_{\mathrm{el}}$, accounts the losses in the induction generator, namely the stator iron losses, the stator and rotor copper losses [53], and the VSD losses. $\left\{\begin{array}{l}\text { Pump mode: } \eta^{\mathrm{P}}=\frac{P_{\mathrm{h}}}{P} ; \eta_{\mathrm{el}}^{\mathrm{P}}=\frac{P}{P_{\text {sup }}} ; \eta_{\mathrm{g}}^{\mathrm{P}}=\frac{P_{\mathrm{h}}}{P_{\text {sup }}} \\ \text { Turbine mode: } \eta^{\mathrm{T}}=\frac{P}{P_{\mathrm{h}}} ; \eta_{\mathrm{el}}^{\mathrm{T}}=\frac{P_{\text {sup }}}{P} ; \eta_{\mathrm{g}}^{\mathrm{T}}=\frac{P_{\text {sup }}}{P_{\mathrm{h}}}\end{array}\right.$

Measurements are performed under cavitation-free conditions. The Net Positive Suction Energy NPSE is defined by:

$N P S E=\frac{p_{\mathrm{abs}, 2}-p_{\mathrm{va}}}{\rho_{2}}+\frac{C_{2}^{2}}{2}-g\left(z_{\mathrm{ref}}-z_{2}\right)$

where $p_{v a}$ is the vapour pressure, which is a function of the temperature $\theta$ [51], and $z_{\text {ref }}$ is the reference elevation of the PAT. According to the measurement setup of Fig. 8, the NPSE is computed by Eq. (10). Consequently, the Thoma Number, $\sigma$, is obtained by Eq. 
Table 7

BEP measurements of the turbine mode for $N$ values between $1500 \mathrm{~min}^{-1}$ and $3000 \mathrm{~min}^{-1}$. Values inside parentheses indicate the total relative errors.

\begin{tabular}{|c|c|c|c|c|c|c|c|c|c|}
\hline Pump ID & $N\left(\min ^{-1}\right)$ & $Q\left(1 \cdot \mathrm{s}^{-1}\right)$ & $E\left(\mathrm{~J} \cdot \mathrm{kg}^{-1}\right)$ & $T(\mathrm{~N} \cdot \mathrm{m})$ & $P(\mathrm{~kW})$ & $\eta^{T}(\%)$ & $n_{E D}(-)$ & $Q_{E D}(-)$ & $T_{E D}(-)$ \\
\hline \multirow[t]{6}{*}{$n_{\mathrm{q}}=23.1$} & $1500( \pm 0.4 \%)$ & $9.0( \pm 1.8 \%)$ & $130.8( \pm 0.8 \%)$ & $5.1( \pm 2.9 \%)$ & $0.8( \pm 0.1 \%)$ & $68.1( \pm 3.5 \%)$ & $0.14( \pm 0.9 \%)$ & $0.19( \pm 1.9 \%)$ & $0.14( \pm 3.0 \%)$ \\
\hline & $1800( \pm 0.3 \%)$ & $11.0( \pm 1.5 \%)$ & $189.9( \pm 0.6 \%)$ & $7.7( \pm 1.9 \%)$ & $1.5( \pm 0.2 \%)$ & $69.8( \pm 2.5 \%)$ & $0.14( \pm 0.7 \%)$ & $0.19( \pm 1.6 \%)$ & $0.15( \pm 2.0 \%)$ \\
\hline & $2100( \pm 0.3 \%)$ & $13.1( \pm 1.2 \%)$ & $263.5( \pm 0.4 \%)$ & $11.1( \pm 1.4 \%)$ & $2.4( \pm 0.2 \%)$ & $70.7( \pm 1.9 \%)$ & $0.14( \pm 0.5 \%)$ & $0.19( \pm 1.3 \%)$ & $0.15( \pm 1.4 \%)$ \\
\hline & $2400( \pm 0.2 \%)$ & $15.0( \pm 1.1 \%)$ & $346.0( \pm 0.3 \%)$ & $14.6( \pm 1.0 \%)$ & $3.7( \pm 0.2 \%)$ & $70.9( \pm 1.5 \%)$ & $0.14( \pm 0.4 \%)$ & $0.19( \pm 1.1 \%)$ & $0.15( \pm 1.1 \%)$ \\
\hline & $2701( \pm 0.2 \%)$ & $16.0( \pm 1.0 \%)$ & $403.8( \pm 0.3 \%)$ & $16.4( \pm 0.9 \%)$ & $4.6( \pm 0.2 \%)$ & $72.0( \pm 1.4 \%)$ & $0.15( \pm 0.4 \%)$ & $0.19( \pm 1.0 \%)$ & $0.15( \pm 1.0 \%)$ \\
\hline & $3001( \pm 0.2 \%)$ & $18.0( \pm 0.9 \%)$ & $504.1( \pm 0.2 \%)$ & $20.8( \pm 0.7 \%)$ & $6.5( \pm 0.3 \%)$ & $72.3( \pm 1.2 \%)$ & $0.14( \pm 0.3 \%)$ & $0.19( \pm 0.9 \%)$ & $0.15( \pm 0.8 \%)$ \\
\hline \multirow{6}{*}{$n_{\mathrm{q}}=41.0$} & $1499( \pm 0.4 \%)$ & $10.0( \pm 1.6 \%)$ & $91.5( \pm 1.2 \%)$ & $3.6( \pm 4.2 \%)$ & $0.6( \pm 0.1 \%)$ & $61.1( \pm 4.7 \%)$ & $0.17( \pm 1.2 \%)$ & $0.25( \pm 2.0 \%)$ & $0.14( \pm 4.4 \%)$ \\
\hline & $1800( \pm 0.3 \%)$ & $11.0( \pm 1.4 \%)$ & $114.1( \pm 0.9 \%)$ & $4.2( \pm 3.5 \%)$ & $0.8( \pm 0.1 \%)$ & $63.8( \pm 3.9 \%)$ & $0.18( \pm 1.0 \%)$ & $0.24( \pm 1.7 \%)$ & $0.14( \pm 3.7 \%)$ \\
\hline & $2100( \pm 0.3 \%)$ & $13.1( \pm 1.2 \%)$ & $156.8( \pm 0.7 \%)$ & $6.1( \pm 2.5 \%)$ & $1.3( \pm 0.1 \%)$ & $65.8( \pm 2.8 \%)$ & $0.18( \pm 0.7 \%)$ & $0.25( \pm 1.4 \%)$ & $0.14( \pm 2.5 \%)$ \\
\hline & $2402( \pm 0.2 \%)$ & $15.0( \pm 1.1 \%)$ & $204.7( \pm 0.5 \%)$ & $8.2( \pm 1.8 \%)$ & $2.1( \pm 0.1 \%)$ & $67.1( \pm 2.2 \%)$ & $0.18( \pm 0.6 \%)$ & $0.25( \pm 1.2 \%)$ & $0.15( \pm 1.9 \%)$ \\
\hline & $2703( \pm 0.2 \%)$ & $16.0( \pm 1.0 \%)$ & $236.4( \pm 0.5 \%)$ & $9.0( \pm 1.7 \%)$ & $2.5( \pm 0.1 \%)$ & $67.5( \pm 2.0 \%)$ & $0.19( \pm 0.5 \%)$ & $0.25( \pm 1.1 \%)$ & $0.14( \pm 1.7 \%)$ \\
\hline & $3005( \pm 0.2 \%)$ & $18.1( \pm 0.9 \%)$ & $298.6( \pm 0.4 \%)$ & $11.8( \pm 1.3 \%)$ & $3.7( \pm 0.2 \%)$ & $69.2( \pm 1.6 \%)$ & $0.19( \pm 0.4 \%)$ & $0.25( \pm 1.0 \%)$ & $0.14( \pm 1.3 \%)$ \\
\hline \multirow[t]{6}{*}{$n_{\mathrm{q}}=67.3$} & $1500( \pm 0.4 \%)$ & $21.9( \pm 0.7 \%)$ & $76.3( \pm 1.4 \%)$ & $7.2( \pm 2.1 \%)$ & $1.1( \pm 0.2 \%)$ & $68.2( \pm 2.6 \%)$ & $0.23( \pm 1.4 \%)$ & $0.39( \pm 1.6 \%)$ & $0.19( \pm 2.5 \%)$ \\
\hline & $1801( \pm 0.3 \%)$ & $25.9( \pm 0.6 \%)$ & $107.3( \pm 1.0 \%)$ & $10.2( \pm 1.5 \%)$ & $1.9( \pm 0.2 \%)$ & $69.4( \pm 1.9 \%)$ & $0.23( \pm 1.0 \%)$ & $0.39( \pm 1.2 \%)$ & $0.19( \pm 1.8 \%)$ \\
\hline & $2100( \pm 0.3 \%)$ & $29.9( \pm 0.5 \%)$ & $142.2( \pm 0.7 \%)$ & $13.4( \pm 1.1 \%)$ & $2.9( \pm 0.3 \%)$ & $69.4( \pm 1.5 \%)$ & $0.23( \pm 0.8 \%)$ & $0.39( \pm 0.9 \%)$ & $0.18( \pm 1.3 \%)$ \\
\hline & $2401( \pm 0.2 \%)$ & $33.9( \pm 0.5 \%)$ & $183.2( \pm 0.6 \%)$ & $17.2( \pm 0.9 \%)$ & $4.3( \pm 0.3 \%)$ & $69.8( \pm 1.2 \%)$ & $0.24( \pm 0.6 \%)$ & $0.39( \pm 0.7 \%)$ & $0.18( \pm 1.0 \%)$ \\
\hline & $2701( \pm 0.2 \%)$ & $39.2( \pm 0.4 \%)$ & $243.9( \pm 0.4 \%)$ & $23.8( \pm 0.6 \%)$ & $6.7( \pm 0.4 \%)$ & $70.7( \pm 0.9 \%)^{*}$ & $0.23( \pm 0.5 \%)$ & $0.39( \pm 0.6 \%)$ & $0.19( \pm 0.8 \%)$ \\
\hline & $3000( \pm 0.2 \%)$ & $39.1( \pm 0.4 \%)$ & $247.0( \pm 0.4 \%)$ & $21.2( \pm 0.7 \%)$ & $6.7( \pm 0.3 \%)$ & $69.3( \pm 0.9 \%)^{*}$ & $0.25( \pm 0.5 \%)$ & $0.39( \pm 0.6 \%)$ & $0.17( \pm 0.8 \%)$ \\
\hline
\end{tabular}

* Maximum efficiency not measured due to discharge limitation in the test-rig.

(11).

$N P S E=\frac{\Delta p_{2}+p_{\mathrm{amb}}-p_{\mathrm{va}}}{\rho_{2}}+\frac{C_{2}^{2}}{2}$

$\sigma=\frac{N P S E}{E}$

where, $p_{\mathrm{amb}}$ is the ambient pressure at the test-site.

The systematic relative error, $f_{X, s}$, is computed for every measured point by Eq. (12). Consequently, the total relative error is given by Eq. (13). This calculation considers a conservatively estimated random error $f_{X, r}=0.1 \%$. Finally, the propagated total relative error of a given parameter is determined based on the root mean square of all the total relative errors of its dependent variables [51].

$f_{X, s}=\frac{e_{X, s}}{\bar{X}}$

$f_{X, t}=\sqrt{\left(f_{X, s}\right)^{2}+\left(f_{X, r}\right)^{2}}$

Being $e_{X,}$ the systematic absolute error (see Table 3 ) and $\bar{X}$ the average value of a measured parameter.

The experimental tests aimed at obtaining the variable speed performance of the three hydraulic machines in pump mode, in turbine mode and in the four quadrants of operation. Each measurement is performed for stationary flow conditions. Each operating point is collected with a sampling frequency of $5 \mathrm{kHz}$ during $20 \mathrm{~s}$. Average and standard deviation values of all measurements are recorded. The temperature variation does not exceed $2{ }^{\circ} \mathrm{C}$ during each test.

The pump mode and turbine mode are both investigated for constant $N$ values ranging from $600 \mathrm{~min}^{-1}$ to $3000 \mathrm{~min}^{-1}$ with steps of $300 \mathrm{~min}^{-1}$. In pump mode, the discharge is gradually increased using a discharge control valve, between each measured point. The by-pass to the feed pumps is open to allow flow circulation in the reverse direction. In turbine mode, the discharge and the specific energy at the PAT inlet are controlled using the VSD of the feed pumps. Measurements are performed for the operating points with positive torque.

The extended operation tests aim at retrieving the $n_{E D}-Q_{E D}$ and the $n_{E D}-T_{E D}$ characteristic curves for the quadrants of operation showed in Table 2. The first quadrant is measured during the pump mode tests. The second quadrant is obtained starting at zero discharge. The feed pumps gradually supply discharge, while the PAT is operating in pumping direction at a constant rotational speed. Measurements for higher values of $Q_{E D}$ are limited by the vibrations in the test-rig. The third quadrant is measured starting at full load conditions and gradually reducing the supplied specific hydraulic energy at the PAT inlet. Near no-load conditions, the performance of the PAT may become unstable. The additional head loss created by a by-pass in the low-pressure pipes stabilizes the operation of the PAT [54]. As the machine reaches zero discharge conditions, the by-pass to the feed pumps is opened to perform measurements in the fourth quadrant.

\section{Results}

\subsection{Pump mode performance}

Experimental tests in pump mode mainly aimed to collect data for further comparison of the efficiency and torque values with the turbine mode. Collected data for the pumps with $n_{\mathrm{q}}$ values of 23.1, 41.0 and 67.3 are given in Fig. 9, Fig. 10 and Fig. 11, respectively. Results given in these figures are represented by the variations of $E$, $T, P$ and $\eta^{P}$ with respect to $Q$. The measured BEP for constant $N$ values between $1500 \mathrm{~min}^{-1}$ and $3000 \mathrm{~min}^{-1}$ are given in Table 5 . Measurements for lower rotational speed values are not presented due to the high uncertainty of the measurements (e.g., $\left.f\left(\eta_{\mathrm{BEP}}^{\mathrm{P}}\right)_{t}>5 \%\right)$.

The maximum power of the tested pumps prevented to carry out measurements for $Q=26.0 \mathrm{l} \cdot \mathrm{s}^{-1}$ (see Fig. 11). The measured values of $\eta^{P}$ are lower than the rated performance provided by the pump manufacturer. Nevertheless, measured values are within the tolerance band of the supplier (Grade 3B of the ISO9906:2012 [55]).

\subsection{Turbine mode performance}

Collected data of the turbine mode performance for the PATs with $n_{\mathrm{q}}$ values of 23.1, 41.0 and 67.3 are presented in Fig. 12, Fig. 13 and Fig. 14, respectively. Results are given by the variations of $E, T, P$ and $\eta^{\mathrm{T}}$ with respect to $Q$. The BEP for $N$ between $1500 \mathrm{~min}^{-1}$ and $3000 \mathrm{~min}^{-1}$ are given in Table 7 . 


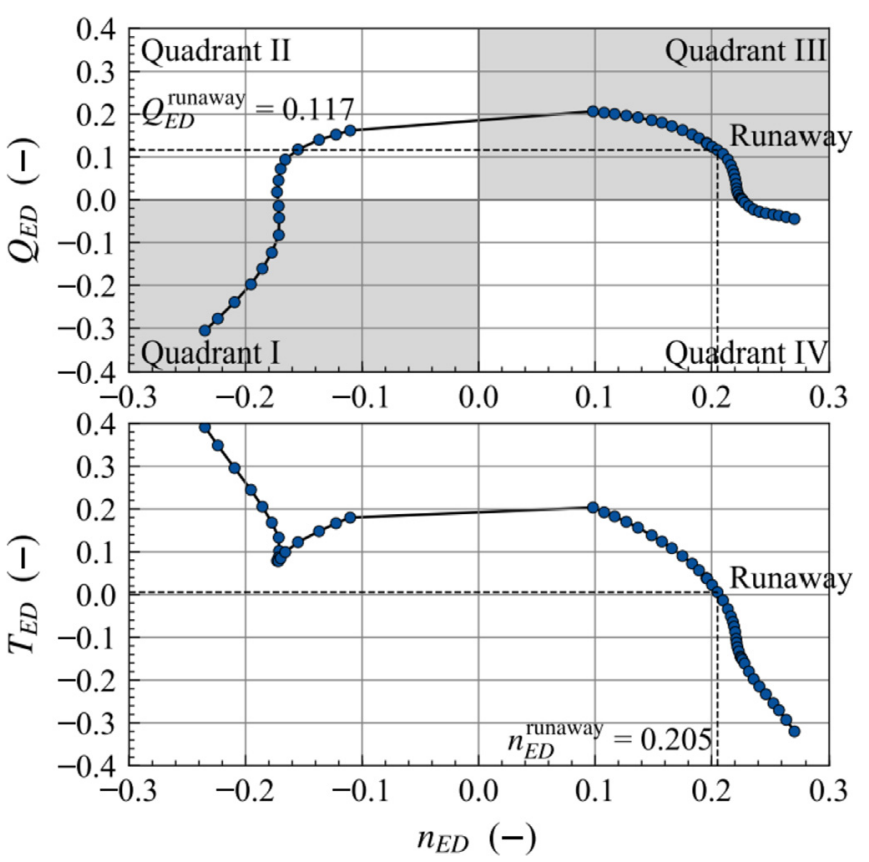

Fig. 15. Experimental results in the four quadrants of the $n_{\mathrm{q}}=23.1$ pump.

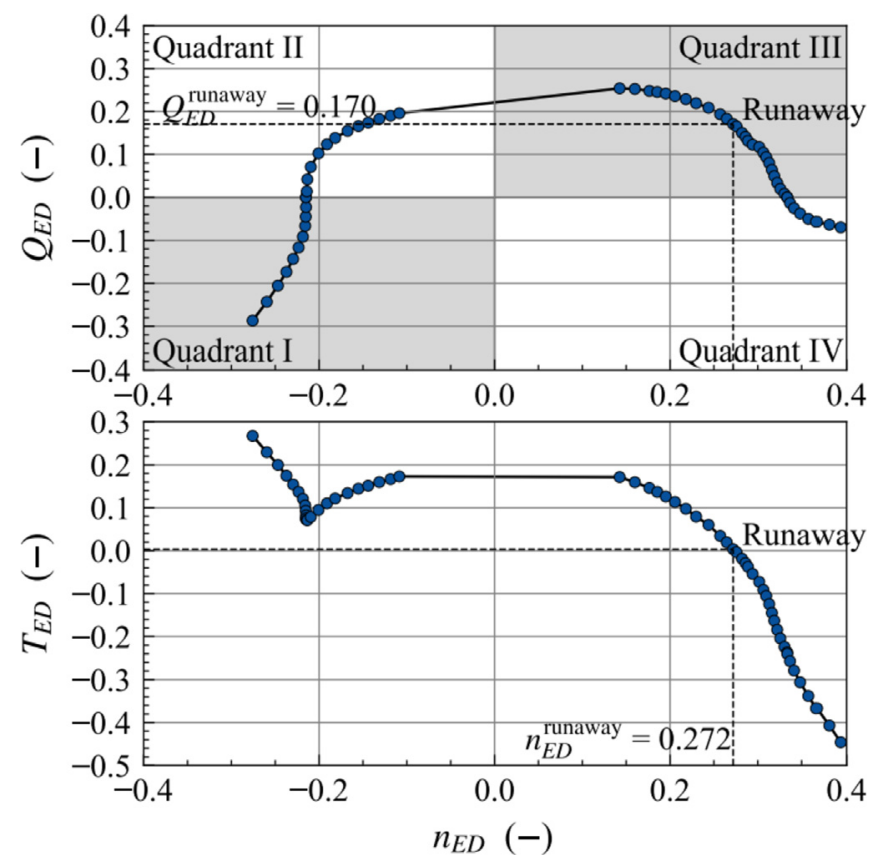

Fig. 16. Experimental results in the four quadrants of the $n_{\mathrm{q}}=41.0$ pump.

The BEP in the turbine mode is observed at higher values of $E$ and $Q$ than in the pump mode (see Tables 5 and 7). All pumps achieved the same orders of magnitude in the maximum efficiency values in both modes, as illustrated in Table 6 . The maximum efficiency deviation $\Delta \eta_{\max }=\eta_{\max }^{\mathrm{T}}-\eta_{\max }^{\mathrm{P}}$, is in the range of $\pm 5 \%$, which is in agreement with results reported in the literature [56].

The variable speed operation extends the operating range of the PATs. On the one hand, it increases the efficiency for smaller discharge values. For instance, the efficiency of the $n_{\mathrm{q}}=67.3$ PAT at $Q=25.0 \mathrm{l} \cdot \mathrm{s}^{-1}$ is $\eta^{\mathrm{T}}=36.2 \%$ and $\eta^{\mathrm{T}}=69.1 \%$, for $N=1800 \mathrm{~min}^{-1}$ and $N=3000 \mathrm{~min}^{-1}$, respectively (see Fig. 14).
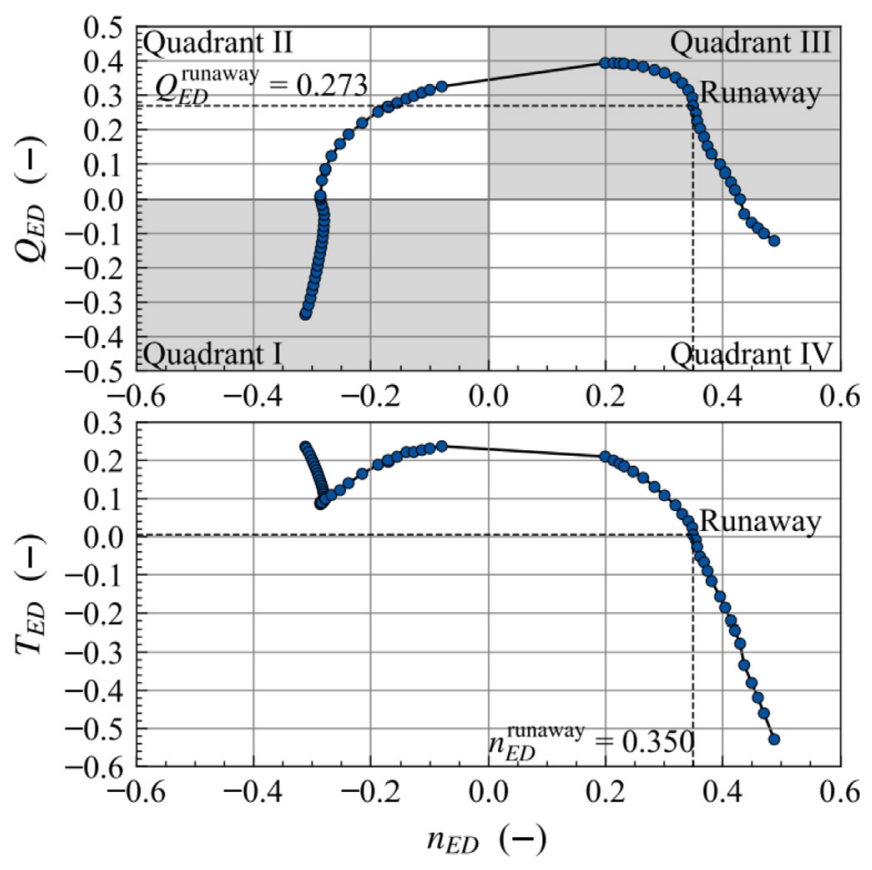

Fig. 17. Experimental results in the four quadrants of the $n_{\mathrm{q}}=67.3$ pump.
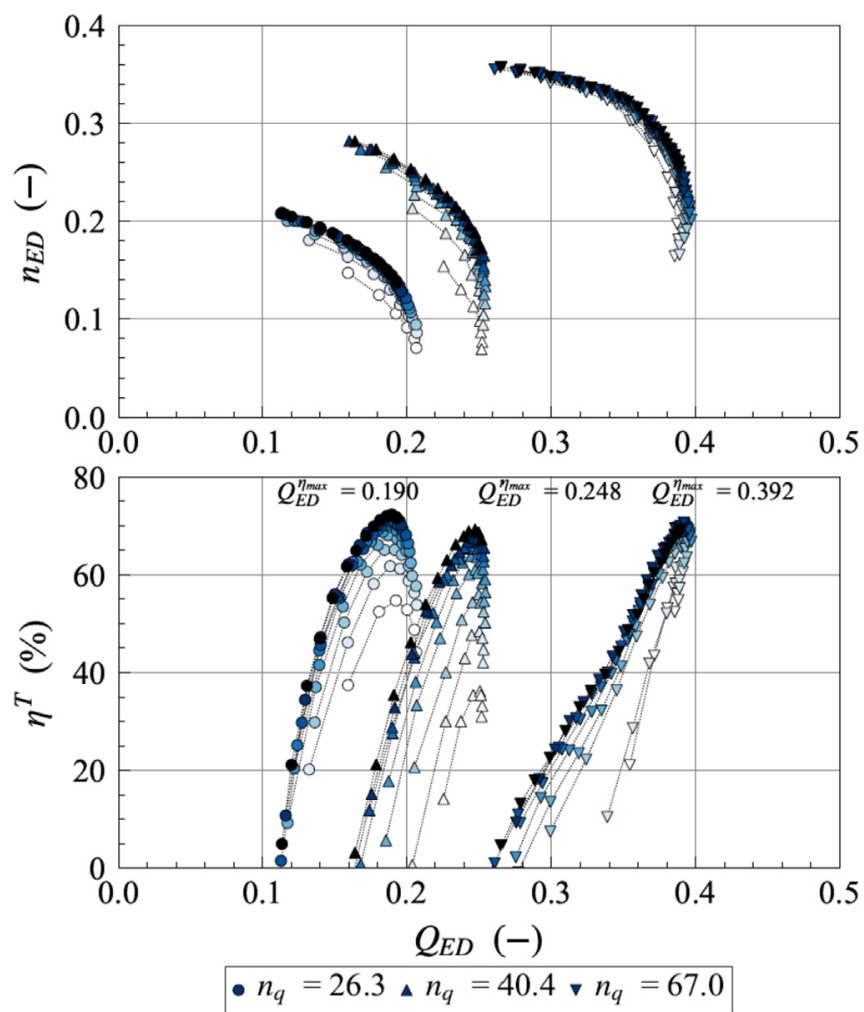

Fig. 18. Performance of the PATs in generating mode represented by $n_{E D}$ and $\eta^{\mathrm{T}}$ with respect to $Q_{E D}$.

Such raise results in an absolute power yield increase from $P=1.25 \mathrm{~kW}$ to $P=1.75 \mathrm{~kW}$ (corresponding to a relative increase of 38.5\%). On the other hand, the speed control increases the range of deployable $E$ values in the WSS. For instance, the $n_{\mathrm{q}}=23.1$ PAT can only operate at $E<245 \mathrm{~J} \cdot \mathrm{kg}^{-1}$ if the machine runs at lower values of $N$ compared to the rated rotational speed (i.e., $N=3000$ 


$$
Q=0.039 \mathrm{~m}^{3} \cdot \mathrm{s}^{-1}, N=3000 \mathrm{~min}^{-1}, \sigma=2.0
$$

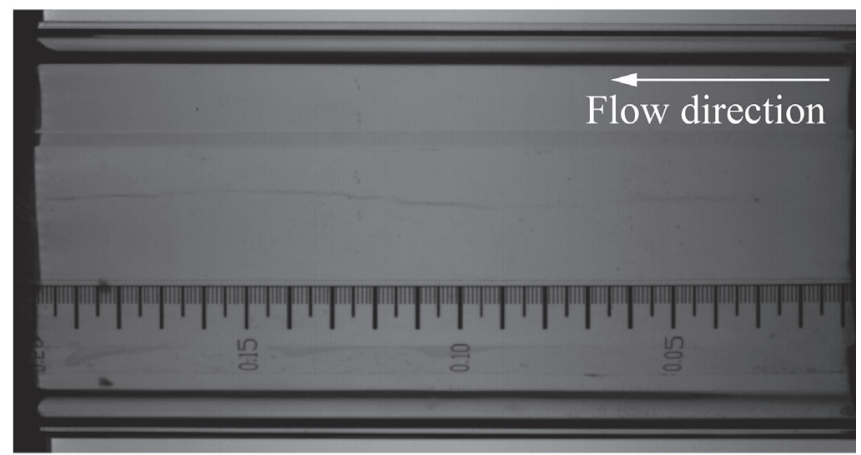

$$
Q=0.030 \mathrm{~m}^{3} \cdot \mathrm{s}^{-1}, N=3000 \mathrm{~min}^{-1}, \sigma=2.0
$$

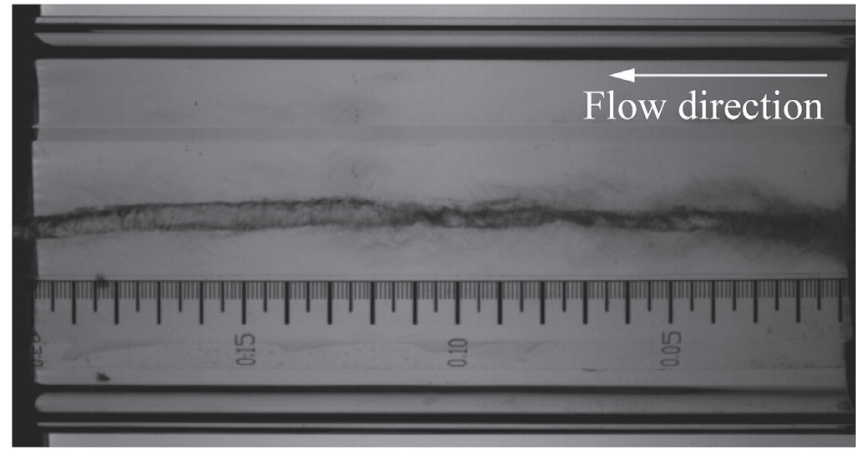

$Q=0.027 \mathrm{~m}^{3} \cdot \mathrm{s}^{-1}, N=3000 \mathrm{~min}^{-1}, \sigma=2.0$

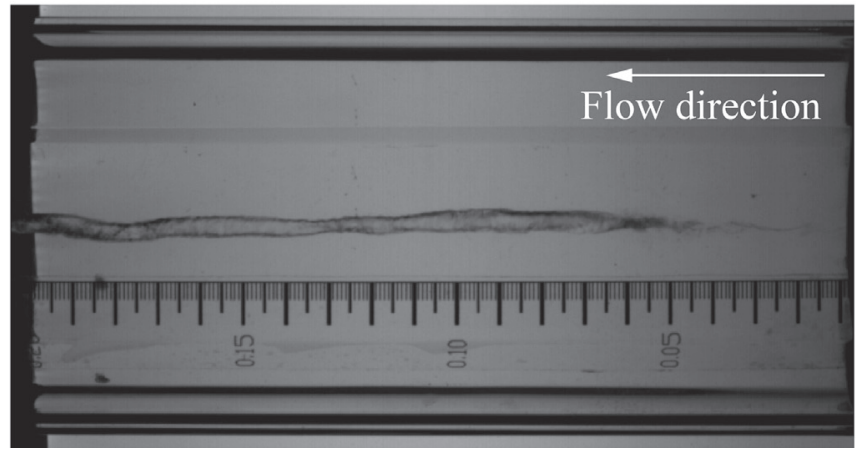

Fig. 19. Vortex rope cavitation visualised for the $n_{\mathrm{q}}=67.3$ PAT at the low pressure side in part load conditions.

$\min ^{-1}$ ) (see Fig. 12).

\subsection{Extended operation}

Collected data of the four quadrants of operation for the pumps with $n_{\mathrm{q}}$ values of 23.1, 41.0 and 67.3 are presented in Fig. 15, Fig. 16 and Fig. 17, respectively. Results are given by the variations of the factors $Q_{E D}$ and $T_{E D}$, with respect to $n_{E D}$. Furthermore the speed and discharge factors at the runaway conditions, $n_{E D}^{\text {runaway }}$ and $Q_{E D}^{\text {runaway }}$ respectively, are provided in the figures. This experimental data refer to the PATs performance with $N=2100 \mathrm{~min}^{-1}$. The shape of the $n_{E D}-Q_{E D}$ and the $n_{E D}-T_{E D}$ characteristic curves are similar for all pumps. It is worth to notice that none of the PATs features the unstable characteristic curve defined by $\partial Q_{E D} / \partial n_{E D}>0$ near the runaway point. Moreover, both $n_{E D}^{\text {runaway }}$ and $Q_{E D}^{\text {runaway }}$ values
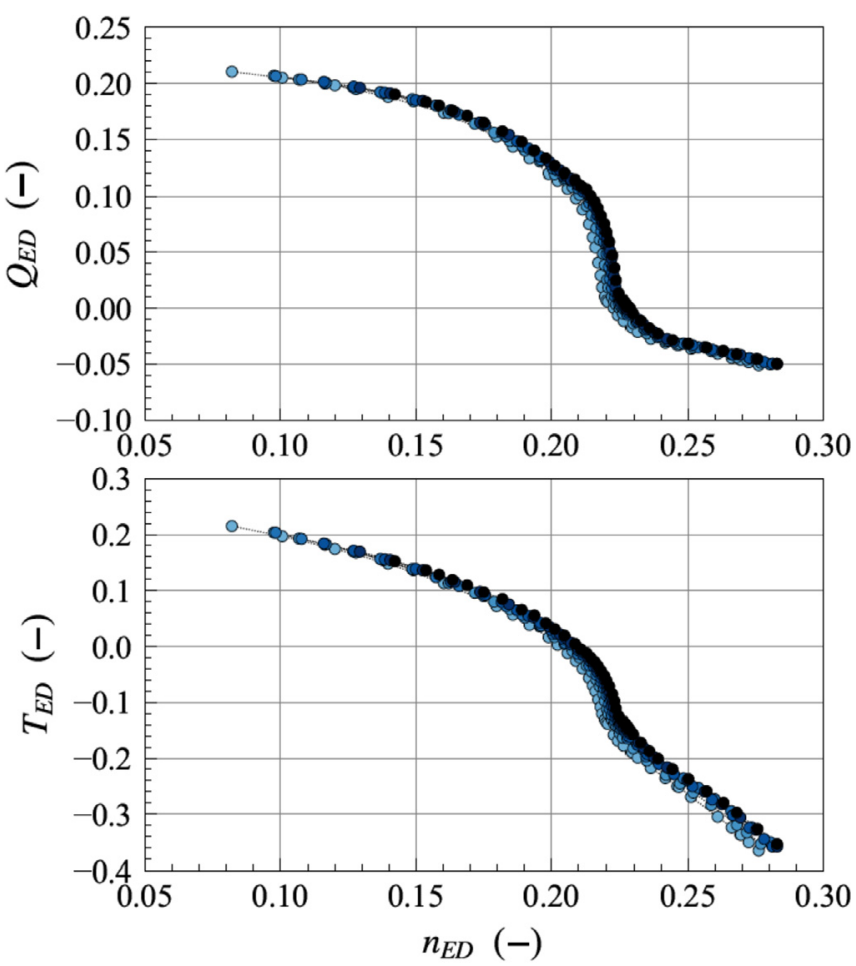

- $1500 \mathrm{~min}^{-1} \cdot 1800 \mathrm{~min}^{-1} \bullet 2100 \mathrm{~min}^{-1}$ - $2400 \mathrm{~min}^{-1} \cdot 2700 \mathrm{~min}^{-1} \bullet 3000 \mathrm{~min}^{-1}$

Fig. 20. Effect of variable speed in the third and fourth quadrant of the $n_{\mathrm{q}}=23.1$ pump.
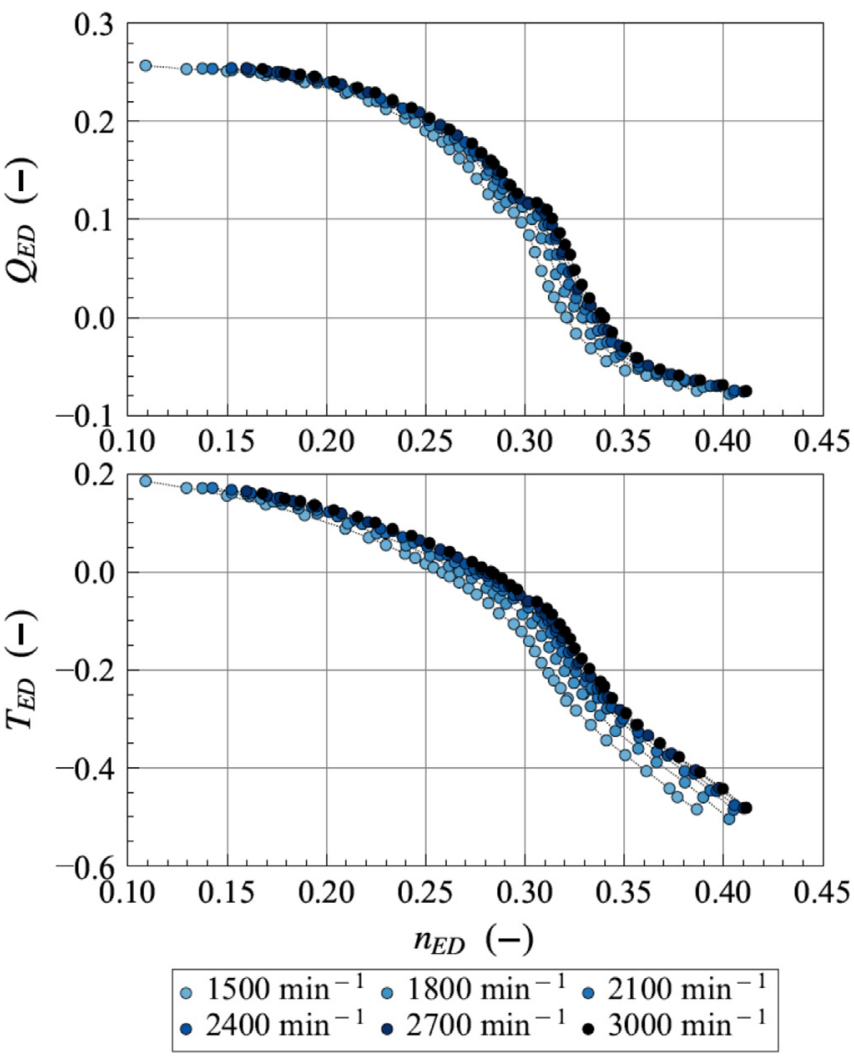

Fig. 21. Effect of variable speed in the third and fourth quadrant of the $n_{\mathrm{q}}=41.0$ pump. 

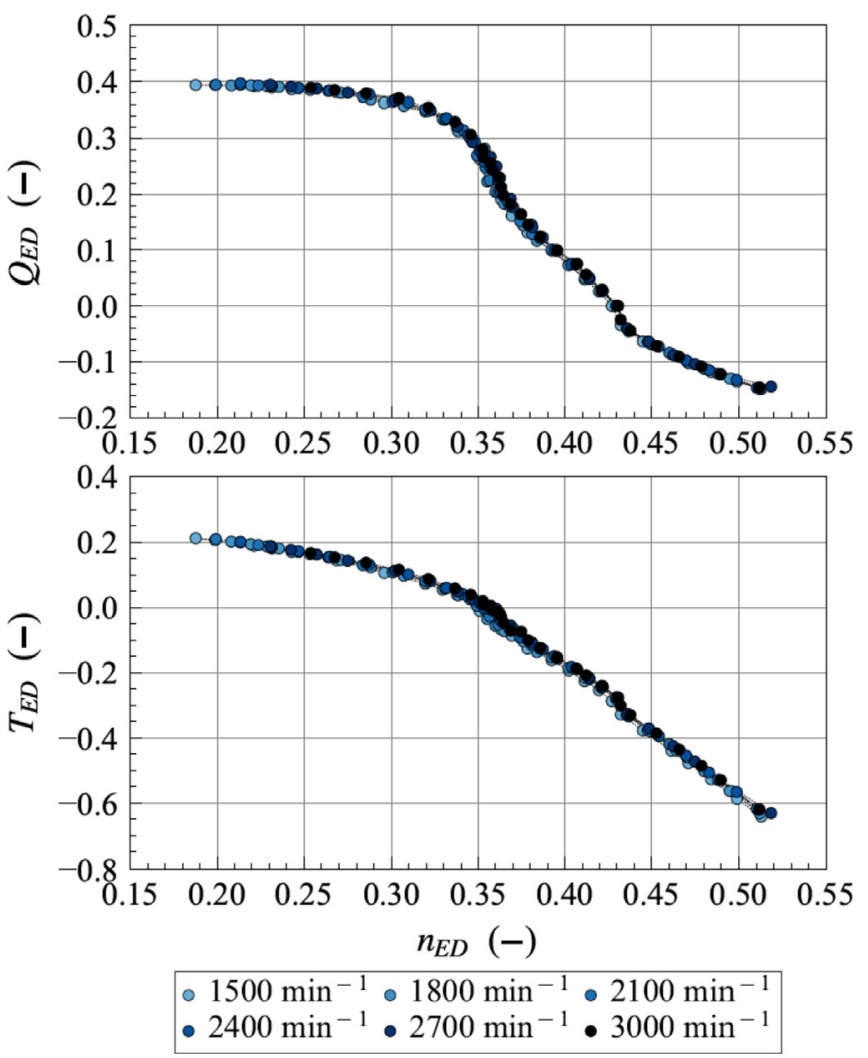

Fig. 22. Effect of variable speed in the third and fourth quadrant of the $n_{\mathrm{q}}=67.3$ pump.

increase with increasing unit specific speed.

\section{Discussion}

\subsection{Variable speed operation in turbine mode}

The variable speed operation in turbine mode increases the range of operation in both the discharge and the specific energy domain while increasing its operating efficiency. The performance of the three PATs is summarised in Fig. 18. The data in this figure makes apparent that the maximum efficiency increases with increasing speed, and is obtained at constant $Q_{E D}$ values. These values are provided in Fig. 18 for all PATs. The variable speed PAT performance is given by constant $Q_{E D}-n_{E D}$ characteristic curves. However, for $N=600 \mathrm{~min}^{-1}$ and $N=900 \mathrm{~min}^{-1}$ these curves are slightly deviated. This could be explained by the Reynolds effects, as the discharge is small for these rotational speed values.

Furthermore, the efficiency significantly drops in off-design operation, if the PAT is operated with constant rotational speed. The efficiency drop is sharper with decreasing values of $n_{\mathrm{q}}$ in partload operation, whilst this feature is more pronounced in full load operation with increasing values of $n_{\mathrm{q}}$. As earlier mentioned, the sharp efficiency decrease is related to the impeller blades leading edge flow incidence and the swirling flow at the PAT outlet. In fact, the swirling flow is perceptible during the part load operation, as illustrated in Fig. 19. The flow visualisations refer to the $n_{\mathrm{q}}=67.0$ PAT with similar backpressure conditions, given by $\sigma=2.0$.

\subsection{Extended operation}

Collected data for the variable speed operation in the third and fourth quadrants are presented in Fig. 20, Fig. 21 and Fig. 22, for the pumps with $n_{\mathrm{q}}$ values of 23.1, 41.0 and 67.3, respectively. Measurements are performed at constant $N$ values ranging from $1500 \mathrm{~min}^{-1}$ to $3000 \mathrm{~min}^{-1}$. Similarly to the turbine mode, the PATs extended performance is given by constant $n_{E D}-Q_{E D}$ and $n_{E D}-T_{E D}$ characteristic curves, except for the $n_{\mathrm{q}}=41.0$ pump. The analysis of the relative total errors of the $n_{E D}$ and $Q_{E D}$ parameters, presented in Fig. 23, makes apparent that the leftward deviation of the extended operation curves is not within the error bands. Further measurements should be performed to determine if this is due to an error during the measurements of this pump. Nevertheless, the unstable feature of $\partial Q_{E D} / \partial n_{E D}>0$ is not observed for any of the pumps.

\section{Conclusions and perspectives}

This research work presents the experimental investigation of

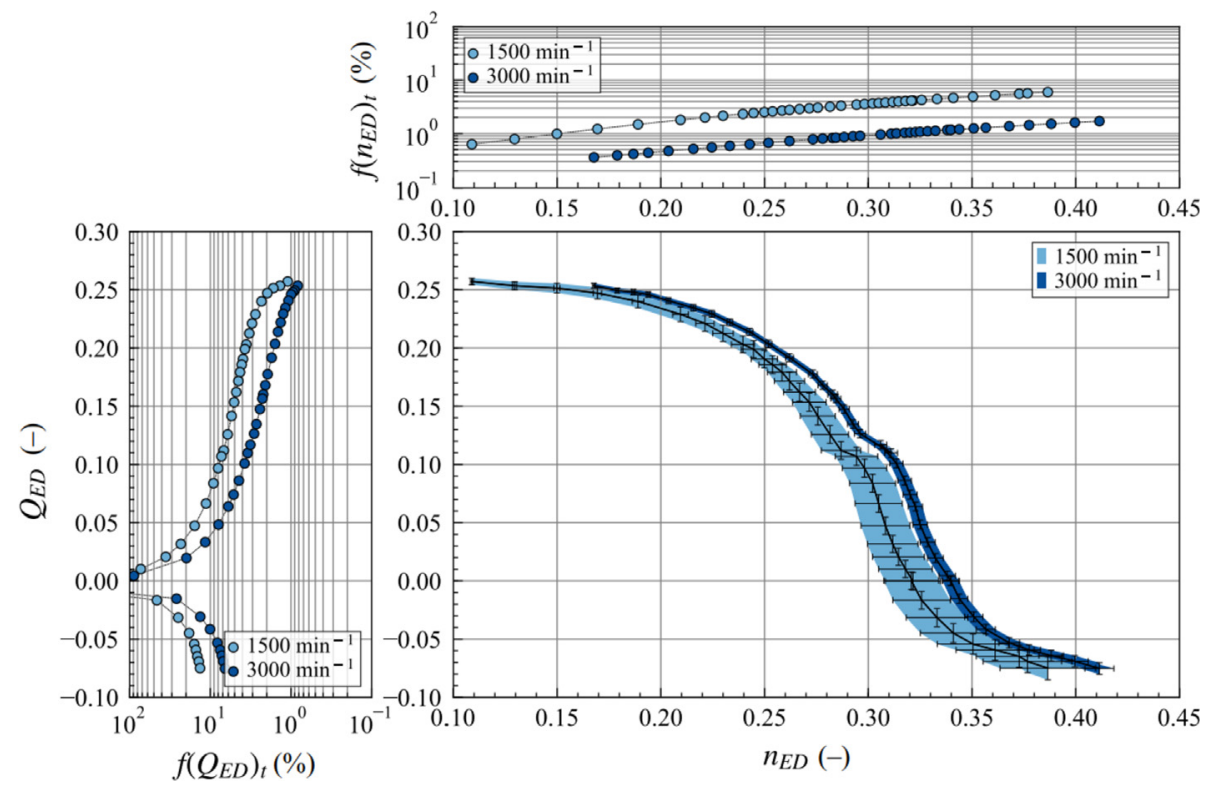

Fig. 23. Measurement error in the third and fourth quadrant of $n_{\mathrm{q}}=41.0$ pump. 
the stationary performance of variable speed PAT operation. The experimental tests are performed in three single-stage end-suction closed-impeller centrifugal pumps with different unit specific speed values, focusing on turbine mode and on the extended operation performance.

The collected data in the turbine mode has put in evidence that the variable speed operation is an operational control capable of increasing the PAT efficiency and the power yield, if these machines are operated in the variable discharge conditions of WSS. Firstly, the variable speed control allows widening the discharge-specific energy operating range, while increasing the efficiency under part load and full load operating conditions. This performance improvement is particularly relevant if the PAT is installed for dynamically controlling the discharge or the pressure in a WSS [57,58], for the optimal management of the water supply. Further research is suggested on the development of a control algorithm that can efficiently control the discharge or pressure downstream the PAT, depending on the real-time requirements of the WSS, while maximising the energy recovered. Turbine mode results show that the maximum efficiency in the turbine mode is in the same order of magnitude as in the pump mode. Also, the maximum efficiency for every set-point of $N$ is obtained at constant values of $Q_{E D}$. This feature may be used for the establishment of the rotational speed control algorithm.

Results of the extended operation mode make evidence that the tested PATs do not show evidence of the unstable feature near the runaway conditions described by $\partial Q_{E D} / \partial n_{E D}>0$. This conclusion is a major advantage for the stability of the start-up and shut down manoeuvres of the PAT hydropower plant.

The obtained results are currently being applied for the development of analytical models, which can describe the variable speed performance of this type of PATs, under the range of $n_{\mathrm{q}}$ values tested. These models can be used both for: (i) evaluating the energy yield of a variable speed PAT hydropower plant; (ii) provide the specification for the pressure control in a WSS with a variable speed PAT system (iii) provide the specifications for the start-up and shutdown manoeuvres; or (iv) assess the hydraulic transient effects in the micro hydropower system due to emergency operation. This will allow to compare the effectiveness of different system layouts and operating strategies (e.g., fixed-speed with a by-pass to the main pipe vs variable speed control), which is still an open research topic.

\section{Declaration of interest}

Authors declare no conflict of interest.

\section{Acknowledgements}

The authors acknowledge Portuguese national funding agency for science, research and technology (FCT) and the Laboratory for Hydraulic Machines for funding João Delgado PhD grant, under the joint doctoral programme H2Doc (PD/00206/2012) between Instituto Superior Técnico (IST) and École Polytechnique Fédérale de Lausanne (EPFL). The authors also acknowledge the European Commission's LIFE Programme for funding LIFE Smart Water Supply System project (LIFE14 ENV/PT/000508) for co-funding the experimental research carried out.

\section{Nomenclature}

$C_{1}, C_{2} \quad$ Flow velocity at the high and low pressure section $\left(\mathrm{m} \cdot \mathrm{s}^{-1}\right)$
D Reference diameter of the PAT. Considered the outlet diameter $(\mathrm{m})$

E Specific hydraulic energy $\left(\mathrm{J} \cdot \mathrm{kg}^{-1}\right)$

$f_{X, t} \quad$ Total relative error of a given parameter $X(-)$

$g \quad$ Gravity acceleration $\left(\mathrm{m} \cdot \mathrm{s}^{-2}\right)$

H Head (m)

$J \quad$ pump moment of inertia $\left(\mathrm{kg} \cdot \mathrm{m}^{-2}\right)$

$n \quad$ Rotational speed $(\mathrm{Hz})$

$n_{E D}, P_{E D}, Q_{E D}, T_{E D}$ Non-dimensional factor of speed, power, discharge and torque $(-)$

$n_{\mathrm{q}} \quad$ Unit specific speed (SI)

$N \quad$ Rotational speed $\left(\mathrm{min}^{-1}\right)$

NPSE Net positive suction energy $\left(\mathrm{J} \cdot \mathrm{kg}^{-1}\right)$

$p_{\mathrm{abs}, 1}, p_{\mathrm{abs}, 2}$ Absolute pressure at the high and low pressure section (Pa)

$p_{\mathrm{amb}} \quad$ Ambient pressure $(\mathrm{Pa})$

$p_{\mathrm{va}} \quad$ Vapour pressure $(\mathrm{Pa})$

$P \quad$ Shaft power $(\mathrm{kW})$

$P_{\mathrm{h}} \quad$ Hydraulic power $(\mathrm{kW})$

$P_{\text {sup }} \quad$ Supplied active electric power $(\mathrm{kW})$

Q Discharge $\left(\mathrm{m}^{3} \cdot \mathrm{s}^{-1}\right)$

$Q_{\mathrm{BEP}} \quad$ Discharge at the best efficiency point $\left(\mathrm{m}^{3} \cdot \mathrm{s}^{-1}\right)$

$Q_{\text {sup }} \quad$ Supplied reactive electric power $(\mathrm{kVAr})$

$T \quad$ Shaft torque $(\mathrm{N} \cdot \mathrm{m})$

$T_{\mathrm{el}} \quad$ Load torque $(\mathrm{N} \cdot \mathrm{m})$

$z_{1}, z_{2}, z_{\text {ref }}$ Elevations of the high and low pressure section and the PAT reference section $(\mathrm{m})$

$\Delta p_{1} \quad$ Differential pressure between the high and the low pressure sections $(\mathrm{Pa})$

$\Delta p_{1} \quad$ Differential pressure between the low pressure section and the reference level $(\mathrm{Pa})$

$\eta, \eta_{\mathrm{el}}, \eta_{\mathrm{g}}$ Mechanical, electric and global efficiency (-)

$\theta \quad$ Water temperature $\left({ }^{\circ} \mathrm{C}\right)$

$\rho_{1}, \rho_{2} \quad$ Water density at high and low pressure sections of the PAT $\left(\mathrm{kg} \cdot \mathrm{m}^{-3}\right)$

$\sigma \quad$ Thoma number $(-)$

$\omega \quad$ radial velocity $\left(\mathrm{rad} \cdot \mathrm{s}^{-1}\right)$

Acronyms

BEP Best Efficiency Point

PAT Pump running As Turbine

PATs Pumps running As Turbines

VSD $\quad$ Variable Speed Drives

WSS $\quad$ Water Supply Systems

\section{References}

[1] M.R. Nogueira Vilanova, J.A. Perrella Balestieri, Energy and hydraulic efficiency in conventional water supply systems, Renew. Sustain. Energy Rev. 30 (2014) 701-714, https://doi.org/10.1016/j.rser.2013.11.024.

[2] A. McNabola, P. Coughlan, L. Corcoran, C. Power, A. Prysor Williams, I. Harris, et al., Energy recovery in the water industry using micro-hydropower: an opportunity to improve sustainability, Water Pol. 16 (2014) 168, https:// doi.org/10.2166/wp.2013.164.

[3] L. Corcoran, A. Mcnabola, P. Coughlan, Energy recovery potential of the Dublin region water supply network, in: Proc. World Congr. Water, Clim. Energy, 2012. Dublin, Ireland.

[4] M. Rossi, M. Righetti, M. Renzi, Pump-as-turbine for energy recovery applications: the case study of an aqueduct, Energy Procedia 101 (2016) 1207-1214, https://doi.org/10.1016/j.egypro.2016.11.163.

[5] S. Kucukali, Municipal water supply dams as a source of small hydropower in Turkey, Renew. Energy 35 (2010) 2001-2007, https://doi.org/10.1016/ j.renene.2010.01.032.

[6] S.P. Adhau, R.M. Moharil, P.G. Adhau, Mini-hydro power generation on existing irrigation projects: case study of Indian sites, Renew. Sustain. Energy Rev. 16 (2012) 4785-4795, https://doi.org/10.1016/j.rser.2012.03.066. 
[7] C. Power, A. McNabola, P. Coughlan, Development of an evaluation method for hydropower energy recovery in wastewater treatment plants: case studies in Ireland and the UK, Sustain. Energy Technol. Assess. 7 (2014) 166-177, https://doi.org/10.1016/j.seta.2014.06.001.

[8] A. Muhammetoglu, I.E. Karadirek, O. Ozen, H. Muhammetoglu, Full-Scale PAT application for energy production and pressure reduction in a water distribution network, J. Water Resour. Plan. Manag. 143 (2017) 4017040, https:// doi.org/10.1061/(ASCE)WR.1943-5452.0000795.

[9] A.A. Williams, N.P.A. Smith, C. Bird, M. Howard, Pumps as turbines and induction motors as generators for energy recovery in water supply systems, Water Environ. J. 12 (1998) 175-178, https://doi.org/10.1111/j.17476593.1998.tb00169.x.

[10] A. McNabola, P. Coughlan, A.P. Williams, Energy recovery in the water industry: an assessment of the potential of micro-hydropower, Water Environ. J. 28 (2014) 294-304, https://doi.org/10.1111/wej.12046.

[11] N. Carriço, D. Covas, H. Alegre, M. do Céu Almeida, How to assess the effectiveness of energy management processes in water supply systems, J. Water Supply Res. Technol. 63 (2014) 342, https://doi.org/10.2166/aqua.2014.094.

[12] J. Pérez García, A. Cortés Marco, S. Nevado Santos, Use of centrifugal pumps operating as turbines for energy recovery in water distribution networks. Two case study, Adv. Mater. Res. 107 (2010) 87-92. 10.4028/www.scientific.net/ AMR.107.87.

[13] G.S. Allen, C.N. Fay, E. Matys, In-Conduit Hydropower Project - Phase I Report, Holden, Massachusetts, 2013.

[14] S. Parra, S. Krause, F. Krönlein, F.W. Günthert, T. Klunke, Intelligent pressure management by pumps as turbines in water distribution systems: results of experimentation, Water Sci. Technol. Water Supply 6 (2017), ws2017154, https://doi.org/10.2166/ws.2017.154.

[15] K.-J. Chae, I.-S. Kim, X. Ren, K.-H. Cheon, Reliable energy recovery in an existing municipal wastewater treatment plant with a flow-variable microhydropower system, Energy Convers. Manag. 101 (2015) 681-688, https:// doi.org/10.1016/j.enconman.2015.06.016.

[16] T. Ueda, M. Goto, A. Namihira, Y. Hirose, Perspectives of small-scale hydropower generation using irrigation water in Japan, Jpn. Agric. Res. Q JARQ 47 (2013) 135-140, https://doi.org/10.6090/jarq.47.135.

[17] J. Frijns, Intervention Concepts for Energy Saving, Recovery and Generation from the Urban Water System, 2014.

[18] USBR (United States Bureau of Reclamation), Site Inventory and Hydropower Energy Assessment of Reclamation Owned Conduits - Supplement to the "Hydropower Resource Assessment at Existing Reclamation Facilities Report.", 2012. Denver, Colorado.

[19] S. Kucukali, Water supply lines as a source of small hydropower in Turkey: a case study in edremit, World Renew. Energy Congr. (2011) 1400-1407, https://doi.org/10.3384/ecp110571400, 2011, Linköping, Sweden.

[20] P. Marques, F. Carvalho, Energy recovery in irrigation schemes: the case study of Alqueva multipurpose infrastructure (in Portuguese), Jornadas Técnicas APRH. A Engenharia dos Aproveitamentos Hidroagrícolas: actualidade e desafios futuros (2011). http://www.aprh.pt/jt-out-2011/pdf/42.pdf.

[21] UNWWAP (United Nations World Water Assessment Programme), The United Nations World Water Development Report 2014: Water and Energy, 2014.

[22] F. Avellan, Hydraulic Turbomachines Course, École Polytechnique Fédérale de Lausanne, Switzerland, 2014.

[23] H. Ramos, A. Borga, Pumps as turbines: an unconventional solution to energy production, Urban Water 1 (1999) 261-263, https://doi.org/10.1016/S14620758(00)00016-9.

[24] M. Kramer, K. Terheiden, S. Wieprecht, Optimized design of impulse turbines in the micro-hydro sector concerning air detrainment processes, Energy 93 (2015) 2604-2613, https://doi.org/10.1016/j.energy.2015.10.022.

[25] I. Samora, V. Hasmatuchi, C. Münch-Alligné, M.J. Franca, A.J. Schleiss, H.M. Ramos, Experimental characterization of a five blade tubular propeller turbine for pipe inline installation, Renew. Energy 95 (2016) 356-366, https://doi.org/10.1016/j.renene.2016.04.023.

[26] T. Ma, H. Yang, X. Guo, C. Lou, Z. Shen, J. Chen, et al., Development of inline hydroelectric generation system from municipal water pipelines, Energy 144 (2018) 535-548, https://doi.org/10.1016/j.energy.2017.11.113.

[27] E. Vagnoni, L. Andolfatto, S. Richard, C. Münch-Alligné, F. Avellan, Hydraulic performance evaluation of a micro-turbine with counter rotating runners by experimental investigation and numerical simulation, Renew. Energy (2018), https://doi.org/10.1016/j.renene.2018.04.015.

[28] V. Sammartano, C. Aricò, M. Sinagra, T. Tucciarelli, Cross-flow turbine design for energy production and discharge regulation, J. Hydraul. Eng. 141 (2015) 4014083, https://doi.org/10.1061/(ASCE)HY.1943-7900.0000977.

[29] Andritz Hydro, Mini Compact Hydro. Dedicated Solutions for Small Hydropower Plants, 2015. Vienna, Austria.

[30] A.A. Williams, Pumps as turbines for low cost micro hydro power, Renew. Energy 9 (1996) 1227-1234, https://doi.org/10.1016/0960-1481(96)88498-9.

[31] Andritz Hydro, ANDRITZ Pumps Used as Turbines. Energy Efficient in Forward and Reverse Mode, 2017. Graz, Austria.

[32] S. Derakhshan, A. Nourbakhsh, Experimental study of characteristic curves of centrifugal pumps working as turbines in different specific speeds, Exp. Therm. Fluid Sci. 32 (2008) 800-807, https://doi.org/10.1016/ j.expthermflusci.2007.10.004.

[33] F. Pugliese, F. De Paola, N. Fontana, M. Giugni, G. Marini, Experimental characterization of two Pumps as Turbines for hydropower generation, Renew. Energy 99 (2016) 180-187, https://doi.org/10.1016/j.renene.2016.06.051.
[34] O. Fecarotta, A. Carravetta, H.M. Ramos, R. Martino, An improved affinity model to enhance variable operating strategy for pumps used as turbines, J. Hydraul. Res. 54 (2016) 332-341, https://doi.org/10.1080/ 00221686.2016.1141804.

[35] N. Fontana, M. Giugni, D. Portolano, Losses reduction and energy production in water-distribution networks, J. Water Resour. Plan. Manag. 138 (2012) 237-244, https://doi.org/10.1061/(ASCE)WR.1943-5452.0000179.

[36] M. Giugni, N. Fontana, A. Ranucci, Optimal location of PRVs and turbines in water distribution systems, J. Water Resour. Plan. Manag. 140 (2014) 6014004, https://doi.org/10.1061/(ASCE)WR.1943-5452.0000418.

[37] N. Fontana, M. Giugni, L. Glielmo, G. Marini, Real time control of a prototype for pressure regulation and energy production in water distribution networks, J. Water Resour. Plan. Manag. 142 (2016) 4016015, https://doi.org/10.1061 (ASCE)WR.1943-5452.0000651.

[38] O. Fecarotta, C. Aricò, A. Carravetta, R. Martino, H.M. Ramos, Hydropower potential in water distribution networks: pressure control by PATs, Wate Resour. Manag. 29 (2014) 699-714, https://doi.org/10.1007/s11269-0140836-3.

[39] A. Carravetta, H. Ramos, S. Derakhshan, Pumps as Turbines. Fundamentals and Applications, Springer Tracts in Mechanical Engineering, 2018, https://doi.org 10.1007/978-3-319-67507-7.

[40] J. Gallagher, I.M. Harris, a. J. Packwood, a. McNabola, a. P. Williams, A strategic assessment of micro-hydropower in the UK and Irish water industry: identifying technical and economic constraints, Renew. Energy 81 (2015) 808-815, https://doi.org/10.1016/j.renene.2015.03.078.

[41] D. Loureiro, A. Mamade, M. Cabral, C. Amado, D. Covas, A comprehensive approach for spatial and temporal water demand profiling to improve management in network areas, Water Resour. Manag. 30 (2016) 3443-3457, https://doi.org/10.1007/s11269-016-1361-3.

[42] A. Doshi, S. Channiwala, P. Singh, Inlet impeller rounding in pumps as turbines: an experimental study to investigate the relative effects of blade and shroud rounding, Exp. Therm. Fluid Sci. 82 (2017) 333-348, https://doi.org/ 10.1016/j.expthermflusci.2016.11.024.

[43] P. Singh, F. Nestmann, Internal hydraulic analysis of impeller rounding in centrifugal pumps as turbines, Exp. Therm. Fluid Sci. 35 (2011) 121-134, https://doi.org/10.1016/j.expthermflusci.2010.08.013.

[44] A. Carravetta, G. del Giudice, O. Fecarotta, H. Ramos, PAT design strategy for energy recovery in water distribution networks by electrical regulation, Energies 6 (2013) 411-424, https://doi.org/10.3390/en6010411.

[45] S.V. Jain, A. Swarnkar, K.H. Motwani, R.N. Patel, Effects of impeller diameter and rotational speed on performance of pump running in turbine mode, Energy Convers. Manag. 89 (2015) 808-824, https://doi.org/10.1016/ j.enconman.2014.10.036.

[46] M. Kramer, K. Terheiden, S. Wieprecht, Pumps as turbines for efficient energy recovery in water supply networks, Renew. Energy 122 (2018) 17-25, https:// doi.org/10.1016/j.renene.2018.01.053.

[47] ESHA - European Small Hydropower Association, Energy Recovery in Existing Infrastructures with Small Hydropower Plants, 2010. Retrieved from, http:/ www.esha.be/fileadmin/esha_files/documents/SHAPES/Multipurpose\% 20schemes\%20brochure\%20SHAPES.pdf.

[48] C. Nicolet, Hydroacoustic Modeling and Numerical Simulation of Unsteady Operation of Hydroelectric Systems, Ph.D Thesis No. 3751, EPFL, Lausanne, Switzerland, 2007.

[49] V. Hasmatuchi, Hydrodynamics of a Pump-Turbine Operating at Off-Design Conditions in Generating Mode, Ph.D thesis No. 5373, EPFL, Lausanne, Switzerland, 2012.

[50] National Instruments, Queued Message Handler Template Documentation, 2017. http://www.ni.com/tutorial/53391/en/. (Accessed 29 June 2017).

[51] IEC (International Electrotechnical Commission), Hydraulic Turbines, Storage Pumps and Pump-Turbines - Model Acceptance Tests, second ed., Int Stand IEC 60193, 1999.

[52] J.F. Gülich, Centrifugal Pumps, second ed., Springer Berlin Heidelberg, Berlin, Heidelberg, 2010 https://doi.org/10.1007/978-3-642-12824-0.

[53] Y. Guan, Z.Q. Zhu, I.A.A. Afinowi, J.C. Mipo, P. Farah, Difference in maximum torque-speed characteristics of induction machine between motor and generator operation modes for electric vehicle application, Electr. Power Syst. Res. 136 (2016) 406-414, https://doi.org/10.1016/j.epsr.2016.03.027.

[54] V. Hasmatuchi, M. Farhat, P. Maruzewski, F. Avellan, Experimental investigation of a pump-turbine at off-design operating conditions, in: 3rd IAHR Int. Meet. Workgr. Cavitation Dyn. Probl. Hydraul. Mach. Syst., Brno, Czech Republic, 2009, pp. 339-348.

[55] International Organization for Standardization, Rotodynamic Pumps - Hydraulic Performance Acceptance Tests - Grades 1, 2 and 3. ISO 99062012 2012.

[56] S.V. Jain, R.N. Patel, Investigations on pump running in turbine mode: a review of the state-of-the-art, Renew. Sustain. Energy Rev. 30 (2014) 841-868, https://doi.org/10.1016/j.rser.2013.11.030.

[57] A. Carravetta, O. Fecarotta, M. Sinagra, T. Tucciarelli, Cost-benefit analysis for hydropower production in water distribution networks by a pump as turbine, J. Water Resour. Plan. Manag. 140 (2014) 4014002, https://doi.org/10.1061/ (ASCE)WR.1943-5452.0000384.

[58] R. Wright, E. Abraham, P. Parpas, I. Stoianov, Control of water distribution networks with dynamic DMA topology using strictly feasible sequential convex programming, Water Resour. Res. 51 (2015) 9925-9941, https:// doi.org/10.1002/2015WR017466. 